\title{
Co-precipitation Synthesis of Near-infrared Iron Oxide Nanocrystals on Magnetically Targeted Imaging and Photothermal Cancer Therapy via Photoablative Protein Denature
}

\author{
Wei-Jhe Syu'1, Chih-Chia Huang², Jong-Kai Hsiao³, Yao-Chang Lee, Yu-Tsang Huang5, Parthiban \\ Venkatesan ${ }^{1}$, Ping-Shan Lai ${ }^{\text {㷇 }}$ \\ 1. Department of Chemistry, National Chung Hsing University, Taichung City 402, Taiwan \\ 2. Department of Photonics, National Cheng Kung University, Tainan City 701, Taiwan \\ 3. Department of Medical Imaging, Buddhist Tzu Chi General Hospital, Taipei Branch, New Taipei City 231, Taiwan \\ 4. National Synchrotron Radiation Research Center, Hsinchu Science Park, Hsinchu 30076, Taiwan \\ 5. Menglinbeier Clinic, Taichung City 407, Taiwan \\ $\triangle$ Corresponding author: Prof. Ping-Shan Lai, Department of Chemistry, National Chung Hsing University, Taichung City 402, Taiwan E-mail: \\ pslai@email.nchu.edu.tw
}

(C) The author(s). This is an open access article distributed under the terms of the Creative Commons Attribution License (https://creativecommons.org/licenses/by/4.0/). See http://ivyspring.com/terms for full terms and conditions.

Received: 2018.12.08; Accepted: 2019.03.21; Published: 2019.05.25

\begin{abstract}
Near-infrared (NIR)-based nanomaterials that provide efficient tumor ablation for cancer therapy have been reported. However, the issues of biocompatibility of metals or ions in inorganic nanoparticles systems such as copper and gold nanoparticles are still a matter of concern. In this study, we developed a facile and ligand-assisted co-precipitation method to synthesize biocompatible iron oxide (IO) nanocrystals with NIR absorption that provided T2-weighted magnetic resonance (MR) images and photothermal ablation characteristics suitable for cancer theranostics. Our results showed that $150-\mathrm{nm}$ particles can be synthesized and optimized by using different amounts of ligand. NIR-IO nanocrystals of this size showed high photothermal conversion efficiency (21.2\%) and T2-weighted MR contrast (transverse relaxivity value approximately $141 \mathrm{~S}-1$ $\mathrm{mM}-1$ ). The NIR-IO nanocrystals showed no cytotoxicity in HT-29 colorectal cancer cells without irradiation, whereas the viability of cells that received NIR-IO nanocrystals decreased significantly after 808-nm laser irradiation. The mechanism of cell death may involve alterations in protein secondary structure and membrane permeability. For in vivo studies, 4-fold enhanced tumor accumulation was significantly observed of NIR-IO nanocrystals with a magnetic field (MF) application, resulting in a 3-fold higher T2-weighted MR signal than that produced by a commercial T2-weighted MR contrast agent (Resovist $($ ) ) and excellent photothermal efficacy (approximately 53 $\left.{ }^{\circ} \mathrm{C}\right)$ for cancer treatment. The innovative NIR-IO nanocrystals showed excellent biocompatibility and have great potential as a theranostic agent against cancer.
\end{abstract}

Key words: photothermal therapy, $\mathrm{Fe}_{3} \mathrm{O}_{4}$ nanocrystals, magnetic field targeting, near-infrared

\section{Introduction}

Enhanced imaging-guided therapy[1, 2] combined with non-invasive treatment to efficiently seek and shrink or cure various types of diseased tissues is highly desired. The theranostic systems for cancer therapy were developed for real time evaluation and optimization of treatment conditions in the period time of treatment and then emerging field toward personalized treatment for the benefit of cancer patients.[3-5] Combined with nanoparticles in minimally invasive treatments and good permeability 
and retention (EPR) effect, many groups reported nano-hybrid systems [6, 7] to approach image-guided therapies against troublesome cancers such as brain tumors has become a goal of clinical trials based on the unique physicochemical treatments of nearinfrared (NIR)-absorption, AC radiofrequency activation, and drug delivery. However, the development of single component nanoparticles for using thermostats remained meet a challenge in the materials synthesis by integrating optical and magnetic features. Although gold-based biomaterials are successful cases for imaging integrated phototherapy [5, 8] e.g., computed tomographyphotothermal therapy (CT-PTT) [9], dark-field imaging-PTT [10], surface enhanced Raman scattering-PTT [11], fluorescence-PTT [12], and multiphoton-photothermal therapy (multiphotonPTT), [13] these gold-based biomaterials required multi-step postsynthesis processes, and cannot be used in non-biological targeting with lower cost such as magnetic field targeting due to lack of magnetic property.

Magnetic iron oxide ( $\mathrm{IO}$ ) nanoparticles have attracted great attention in biomedical applications, such as targeted drug delivery, magnetic resonance imaging (MRI), hyperthermia, and biosensing.[14-16] Our group and many pioneering studies have not only demonstrated the suitability of IO nanoparticles as potential $T_{2}$ contrast agents due to their superparamagnetic behavior and high biocompatibility [17], but also as a basis for magnetic targeting to enhance the accumulation of clinical drugs [18]. In contrast to passive delivery through the enhanced permeability and retention (EPR) of some nanoparticles, which produces a low efficiency of accumulation of therapeutic agents in many cases due to the pathophysiological heterogeneity of tumors [19]. Magnetic nanocomposites combined with external magnetic fields (MFs) [20, 21], provides an advantageous strategy for the active targeting of tumors to overcome the insufficient differences in receptor expression levels among patients for receptor expression between normal and cancerous tissues [18, 20] $\mathrm{Li}$ et al. used this MF strategy to enhance the accumulation of magnetic nanoparticles on the side of a tumor by 3.5-fold compared with that for a method that used the EPR effect[21]. Zhang et al. also reported that the MF strategy could reduce the effective dosage of chemotherapeutics by half $[22,23]$. However, the strategy of MF targeting integrated MRIphotothermal system was rarely reported.

To concern the green mass-production and chemical waste, the IO nanoparticles via aqueous synthesis were exhibited excellent results in recent researches. However, theses aqueous synthesis methods had exist some problems such as size distribution widely or water dispersion poorly due to the two important processs: nucleation and crystalline growth were not being controlled easily [24, 25]. In recent years, the studies of IO nanocarriers had be well studied, however the studies of these IO nanocarriers with photothermal abilty were relative rarely in the area of IO nanocarriers development. Herein, a modified co-precipitation synthesis of IO nanoparticle with high photothermal efficiency was developed by all-in-one reaction of the very low toxic reactants: $\mathrm{FeSO}_{4}$-citrate complex with reductant$\mathrm{NaOH} / \mathrm{TMA}$ solution. It was also demonstrated that ligands not only plays an important role to influence composition and size of nanoparticles depends on reduction/oxidation of ligands to $\mathrm{Fe}^{+2}$ but also control optical properties for the synthesis of NIR IO nanoparticles via partial oxidation co-precipitate approach. In Our results show that the optical absorption features and crystallinity of the particles in the NIR region $(\lambda=650-900 \mathrm{~nm})$ increase with the use of smaller amounts of the reaction ligand (i.e., the $808-\mathrm{nm}$ and $660-\mathrm{nm}$ molar extinction coefficients $(\varepsilon$ values) of the lower citrate experimental group were approximate 9-fold higher than those of the higher citrate experimental group). As expected, the photothermal evaluation results also showed high $\varepsilon$ values for the IO nanocrystals, indicating that they undergo more extensive and more rapid increases in temperature under the same irradiation conditions. Zhou et al. designed $\mathrm{Fe} / \mathrm{Fe}_{3} \mathrm{O}_{4}$ nanoparticles required multiplex modulation on the hydrophobic and hydrophilic surface to achieve to target HeLa tumors, and their experimental results showed excellent photo-stimulated therapeutic efficacy.[26] However, these nanoparticles were synthesized in organic media, an issue of concern for clinical application because a surfactant should be allowable in the preparation process to convert the hydrophobicity of nanoparticles to hydrophilicity. Liao et al. introduced a method of ligand-assisted synthesis in which carboxylate-based ligands were used to increase the interactions between ligand and iron ions to create $\mathrm{IO}$ nanostructures with NIR absorption [27, 28]. However, the particle size obtained using this method was approximately $300-400 \mathrm{~nm}$, which is too large for passive tumor targeting. Several demonstrations are convincing scientific evidence of the photothermal ablation (PTA) for cancer therapy,[27, 29-39] but the studies of efficacy of the magnetic targeting process for improving the PTA and MR imaging of tumor cells during pre-clinical examinations are still less. Herein, to provide a proof-of-concept for the use of MF targeting of tumor sites to greatly enhance PTT efficacy and MR $T_{2}$ contrast imaging in this study, 
mice bearing HT-29 tumors were intravenously injected with NIR-IO nanocrystals and biodistribution, in vitro and in vivo photothermal therapy and MR imaging were evaluated for MF-enhanced cancer theranostics.

\section{Results and Discussion}

\subsection{Synthesis and Characterization of NIR-Activated IO Nanocrystals}

The NIR-IO nanocrystals were synthesized by using $0.11 \mathrm{~g}$ of trisodium citrate (citrate), hydrazine monohydrate $\left(\mathrm{N}_{2} \mathrm{H}_{4}\right)$, and trimesic acid (TMA) as a capping and precipitating agent to react with $\mathrm{FeSO}_{4}$ to produce nanocrystals. In this synthesis procedure, the TMA was acted a gentle oxidant to provide ferrous ions and $\mathrm{N}_{2} \mathrm{H}_{4}$ was acted reducing agent, and finally these agents were removed via dialysis. The absorption spectrum (Figure S1) shows that the NIR-IO nanocrystals absorb light extended to long wavelengths including visible $(660 \mathrm{~nm})$ and NIR $(808$ $\mathrm{nm})$ regions. Band around 660 and $808 \mathrm{~nm}$ are commonly used in PTT and photodynamic therapy (PDT) [21, 26, 40]. To further evaluate the optical properties of the NIR-IO, the extinction coefficient $\varepsilon$ was determined, as listed in Table 1 . The curves of $\varepsilon$ values-wavelength for NIR-IO prepared with $0.11 \mathrm{~g}$ of citrate are presented in Figure 1A, showing 142.49 and
$75.63 \mathrm{M}^{-1} \mathrm{~cm}^{-1}$ at $660 \mathrm{~nm}$ and $808 \mathrm{~nm}$, respectively. These $\varepsilon$ values were higher than those of single-walled carbon nanotubes (CNTs) [41]. The transmission electron microscopy (TEM) results showed small $(\approx 4$ $\mathrm{nm}$ ) and uniform nanocrystals (Figure 1B). Previous research has shown that citrate influences the IO particle size by inhibiting the nucleation process and crystal growth $[25,42]$. Therefore, when high amounts citrates were added to the reaction, smaller nanocrystals were formed via the co-precipitation method.

In addition, the utilization of different concentrations of citrate modified the optical properties of IO citrate into the red-NIR wavelength region (Figure S1). Aqueous NIR-IO solution color was visualized as dark brown, black and orange at $0.0022 \mathrm{~g}$ (A sample), $0.022 \mathrm{~g}$ (B sample) and $0.11 \mathrm{~g}$ (C sample) of citrate groups, respectively (Figure $1 \mathrm{~A}$ insert). The $\varepsilon$ values in the plot of $\varepsilon$ value versus wavelength for NIR-IO increased with decreasing citrate from $0.022 \mathrm{~g}$ to $0.0022 \mathrm{~g}$ and increasing citrate to $0.11 \mathrm{~g}$ in the UV regions (250 to $400 \mathrm{~nm}$ ). Moreover, the higher $\varepsilon$ value at a wavelength of $600-808 \mathrm{~nm}$ was observed for decreasing citrate from $0.11 \mathrm{~g}$ to $0.022 \mathrm{~g}$ (Figure 1A). The NIR-IO nanocrystals displayed high $\varepsilon$ values at a wavelength of $808 \mathrm{~nm}$ and approaching to $650 \mathrm{M}^{-1} \mathrm{~cm}^{-1}$, which can be controlled by varying citrate concentration. Even though the $\varepsilon$ value of the
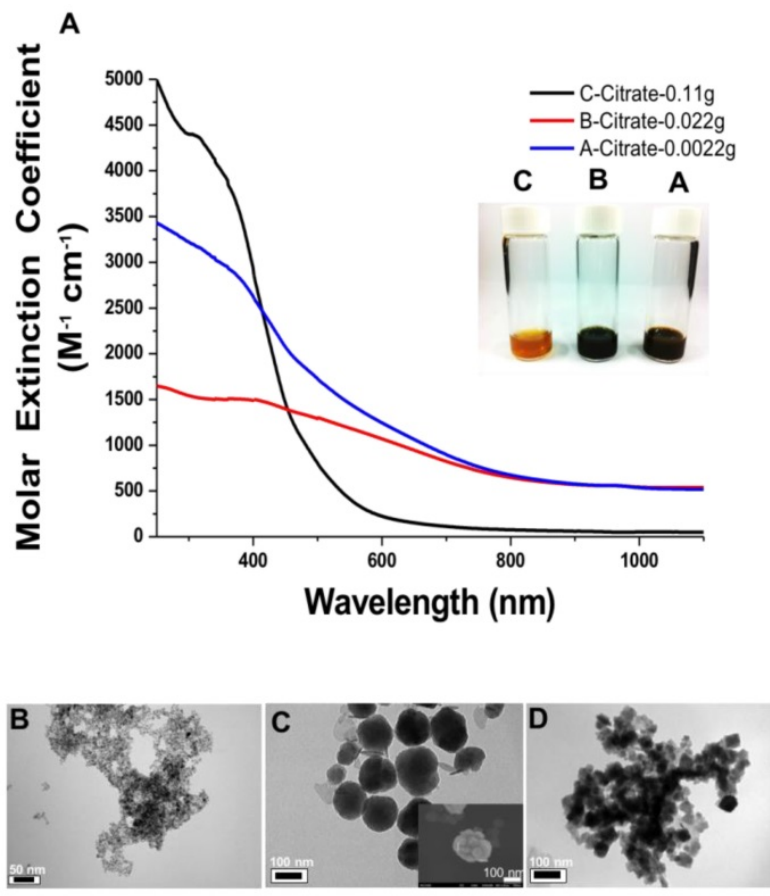

Figure 1. A) Molar extinction coefficient - wavelength diagram and optical image (insert) of NIR-IO nanocrystals. B-D) TEM images of NIR-IO nanocrystals synthesized with $0.11 \mathrm{~g}, 0.022 \mathrm{~g}$ and $0.0022 \mathrm{~g}$ of citrate. The scale bar of $1 \mathrm{~B}$ is $50 \mathrm{~nm}, 1 \mathrm{C}$ and $1 \mathrm{D}$ are $100 \mathrm{~nm}$. E) XRD pattern of NIR-IO nanocrystals synthesized using different amounts of citrate assigned to JCPDS file No. 19-0629. F) FTIR measurement of NIR-IO nanocrystals synthesized using different amounts of citrate. 
NIR-IO nanocrystals at $660 \mathrm{~nm}$ (almost $950 \mathrm{M}^{-1} \mathrm{~cm}^{-1}$ ) was higher than that at $808 \mathrm{~nm}$, the longer irradiation wavelength of $808 \mathrm{~nm}$ has been preferred for cancer therapy due to its stronger tissue penetration. The optical properties of NIR-IO-A (citrate-0.0022 g) group and NIR-IO-B (citrate-0.022 g) group are very similar $(\sim 950 \mathrm{~nm})$ in the wavelength of $808 \mathrm{~nm}$. However, the experimental group of citrate at $0.0022 \mathrm{~g}$ has prone to more aggregation (Figure 1D) owing to the lower availability of citrate to stabilize iron oxide nanoparticles and properties of nanomaterials potential in cancer therapy PTT application.

Intriguingly, the influence of citrate on NIR-IO nanocrystals may result from its effects on nucleation and crystal growth. In a study within the framework of classical nucleation theory, Baumgartner et al. demonstrated the pathway of the primary particles from the bulk phase [43]. They estimated the energy barriers for the nucleation of the amorphous and crystalline phases and proposed that the synthesis of magnetite via co-precipitation occurred by the accretion of clusters/primary particles to form a bulk crystalline phase. In our experiments, we also found that the reflection peak of NIR-IO became sharper with lower values of the citrate concentration during synthesis (Figure 1E). The crystallinity of the NIR-IO nanocrystals decreased when the amount of citrate was increased, suggesting the formation of small IO nanocrystals, consistent with the TEM observations. The large amounts of citrate occupying the surface of the primary particles may have prevented these primary particles from undergoing crystal growth (Figure 1E). The FT-IR result showed absorption at $1630 \mathrm{~cm}^{-1}$, also indicating that more citrate was chelated with the NIR-IO nanocrystals when larger amounts of citrate were used (Figure 1F). These results indicate that citrate can regulate $\mathrm{IO}$ crystallization. However, as shown in the TEM images of NIR-IO in Figure 1D, particles of larger size $(\geq 50 \mathrm{~nm})$ were found when less citrate was added, and large numbers of small-size particles appeared when the amount of citrate was increased.

In addition to showing the influence of citrate on particle size, our results demonstrated the phenomenon of a blueshift in absorption with decreasing particle size. Barnakov and co-workers also used the Faraday rotation spectrum to show similar results concerning the relationship between particle size and optical properties.[44] This change in the optical properties of particles with decreasing size could be due to a decrease in the number of equivalence sites or an increase in the distance between cations and resulting alterations in the intervalence charge transfer (IVCT) [44, 45]. To further investigate the structure of the NIR-IO nanocrystals, high-resolution TEM (HR-TEM) was performed. As shown in Figure 2, particles of small size, irregular shape, and poor crystalline structure were formed when $0.11 \mathrm{~g}$ of sodium citrate was used, whereas nanocrystals with approximately $150 \mathrm{~nm}$ (Figure 1C) and an interplanar distance of $2.1 \AA$ for the (400) planes of fcc-structures $\mathrm{Fe}_{3} \mathrm{O}_{4}$ were obtained when the amount of sodium citrate was decreased to $0.022 \mathrm{~g}$. The aggregation of smaller particles into larger particles (Figure 1C, image insert) was also observed by SEM. Large-scale analysis was also performed using ED measurement, which showed ring- and dot-patterns for the syntheses with sodium citrate at high and low concentrations, respectively (Figure 2). The fast Fourier transform (FFT) pattern of HR-TEM images also provided evidence about crystalline transformation from interplanar distance of $2.9 \AA$ for the (220) planes and $2.5 \AA$ for the (311) planes to amorphous particles via controlling citrate amounts from $0.022 \mathrm{~g}$ to $0.11 \mathrm{~g}$ (Figure S2).

The relationship of ligand to IO nanocrystals was also investigated because ligand chelation influences the optical properties of IO nanocrystals. The FT-IR spectra of NIR-IO nanocrystals prepared with different amounts of citrate were measured (Figure 1F). The absorption bands at $1635 \mathrm{~cm}^{-1}$ (A), $1540 \mathrm{~cm}^{-1}$ (B), and $1405 \mathrm{~cm}^{-1}$ (C) are ascribed to carboxylate groups, whereas the band at $570 \mathrm{~cm}^{-1}$ is caused by $\mathrm{Fe}-\mathrm{O}$ vibrations in $\mathrm{Fe}_{3} \mathrm{O}_{4}$ structure; there, $\mathrm{A}$ and $\mathrm{B}$ correspond to asymmetrical vibrations of carboxylate $\left(\mathrm{v}_{\mathrm{as}}(\mathrm{COO})^{-}\right)$, and $\mathrm{C}$ corresponds to the symmetrical vibration of carboxylate $\left(\mathrm{v}_{\mathrm{s}}(\mathrm{COO})^{-}\right)$[46]. The information obtained from the spectra confirmed that citrate is coordinated with the NIR-IO nanocrystals. Other studies have demonstrated that ligands such as citrate and trimesic acid can enhance surface effects and produce a larger transition probability of $\mathrm{d}-\mathrm{d}$ features for the $\mathrm{Fe}^{+2}$ and $\mathrm{Fe}^{+3}$ ions in the visible-NIR wavelength range [27] Sadat et. al. had reported the detailed electronic bands structure via photoluminescence experiment. The results showed energy of $3.04 \mathrm{eV}$ on $\mathrm{Fe}_{3} \mathrm{O}_{4}$ was attributed via electron transfer from the valence band $\left(\mathrm{O}\left(2_{p}\right)\right.$ to crystal field $\left.\left(e_{g}\right)\right), 2.2 \mathrm{eV}$ was attributed via electron transition from $t_{2 g}$ to $e_{g}$ (octahedral site), and $0.9 \mathrm{eV}$ was attributed via electron transition from $e$ to $t_{2}$ (tetrahedral site). Sadat et. al. also reported $\mathrm{Fe}_{3} \mathrm{O}_{4}$ nanocrystals possess possible of energy levels, $\sim 840 \mathrm{~nm}(1.47 \mathrm{eV})$ by the electron traps on the tetrahedral site, that are associated with the oxygen vacancies [47]. Furthermore, some studies also provided other explanation that NIR-IO nanocrystals possess two possible types of energy levels, $\approx 1200 \mathrm{~nm}$ by $\mathrm{Fe}^{+2}$ ions and $600-900 \mathrm{~nm}$ by ${ }^{6} \mathrm{~A}_{1} \leftrightarrow{ }^{4} \mathrm{~T}_{1}+{ }^{4} \mathrm{~T}_{2}$ of $\mathrm{Fe}^{+3}$ ions $[45,48]$. 

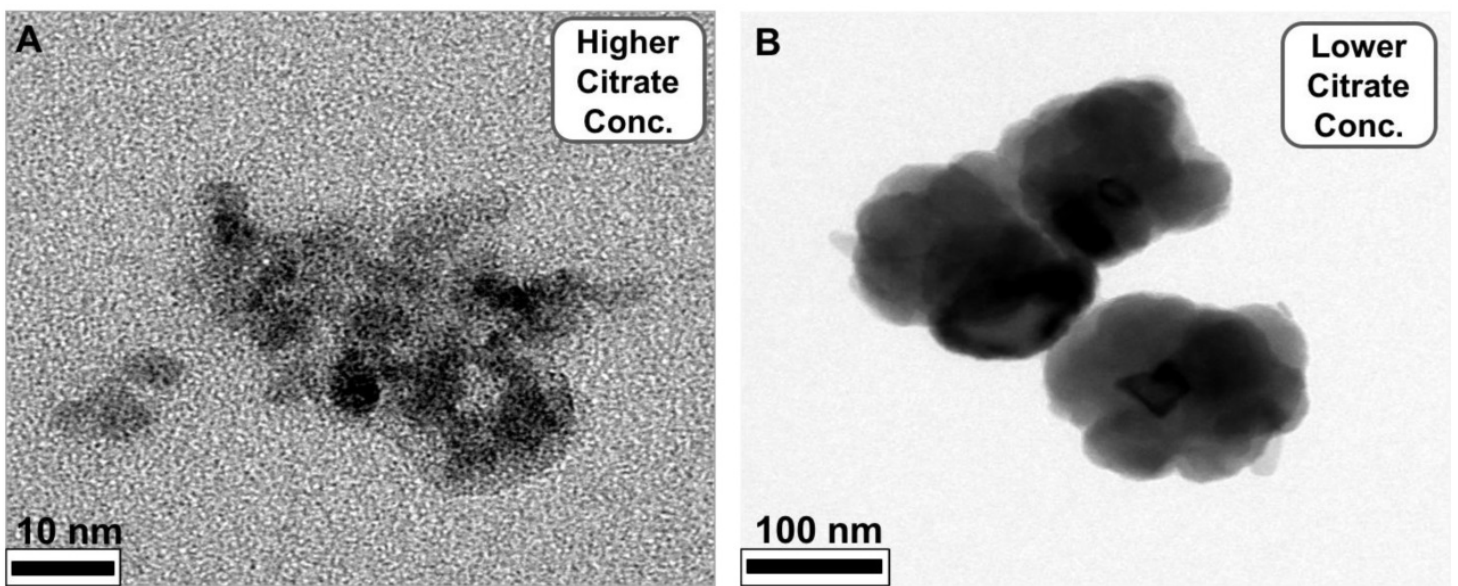

\section{$100 \mathrm{~nm}$}
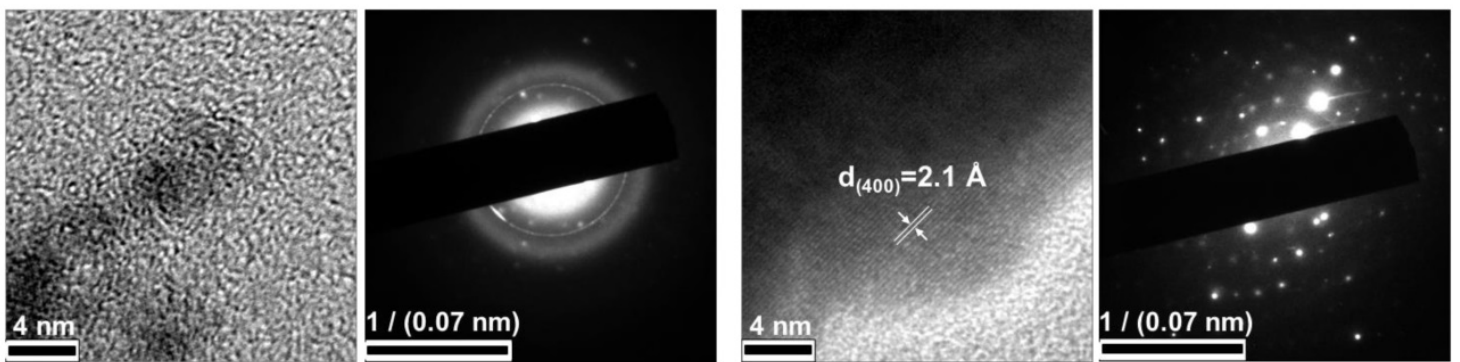

Figure 2. HR-TEM images and ED pattern of NIR-IO nanocrystals obtained via A) high citrate weight $(0.11 \mathrm{~g})$ and B) low citrate weight $(0.022 \mathrm{~g})$ synthesis.

Recently, Chen et al. reported that IO nanocrystals of higher crystallinity provided better NIR absorption, better temperature increase, and higher PTA efficacy because these highly crystalline IO nanocrystals had a preferred plane orientation that resulted in effective absorption of NIR irradiation [49]. In our experiments, we also observed that the NIR optical absorbance of NIR-IO nanocrystals increased when their crystallinity increased. Although the NIR optical properties of NIR-IO nanocrystals might be dominated by their crystallinity, the FT-IR spectra still indicated that citrate was bound to the surfaces of the NIR-IO nanocrystals. The UV-Vis-NIR spectra also showed an obvious alteration in the absorption of NIR-IO nanocrystals at wavelengths of 600-900 nm. Herein, based on these findings, we interpreted ligand-assisted synthesis method to grow NIR-IO nanocrystals (Figure 3). The ferrous ions in the excess citrate environment were protected by ligand chelation, preventing these ions from forming nuclei (seeds). In the crystal growth process, these nuclei would be hydrolyzed due to citrate adsorption, thereby inhibiting the growth of nuclei $[25,42]$. This ligand chelation effect could result in the production of smaller, amorphous particles. When lower amounts of citrate were used, the primary particles could escape citrate protection and enter the crystal growth phase, forming bulk-phase crystalline nanocrystals [43]. Interestingly, two types of NIR-IO nanocrystals also revealed different NIR optical properties. This phenomenon might be caused by an alteration of the crystalline and surface ligand effects. There have been several methods reported to prepare IO nanoparticles with photothermal ability via water phase synthesis using the $\mathrm{Fe}^{2+} / \mathrm{Fe}^{3+}$ co-precipitation along with limited discussion causing the photothermal ability. On other hand, the IO nanoparticles prepared via partial oxidation have limitations for the utilization in biomedical applications, including difficult to control the size distribution and maintain the stability in the blood or microenvironment [51]. Hui et al. synthesized stable IO nanoparticles in aqueous via partial oxidation method; however, the optical property in the NIR-region was not investigated [52]. Gao et al. prepared IO nanoparticles with different size $(60-310 \mathrm{~nm})$ via solvothermal reaction and the results showed that the $\mathrm{IO}$ with larger particle size had higher photothermal ability from the accumulation of different amount of nanoparticles in the tumor area. In addition, optical properties and heating curves were similar for these different sizes of nanoparticles [53]. In this study, we created a ligand-assisted co-precipitation, partial oxidation method to synthesize IO nanocrystals with NIR absorption with high stability in the aqueous enviroment. Ligand (citrate) amounts would also influence on the crystalline of IO nanocrystals and optical properties in NIR region although detail mechanism needs to be investigated. 


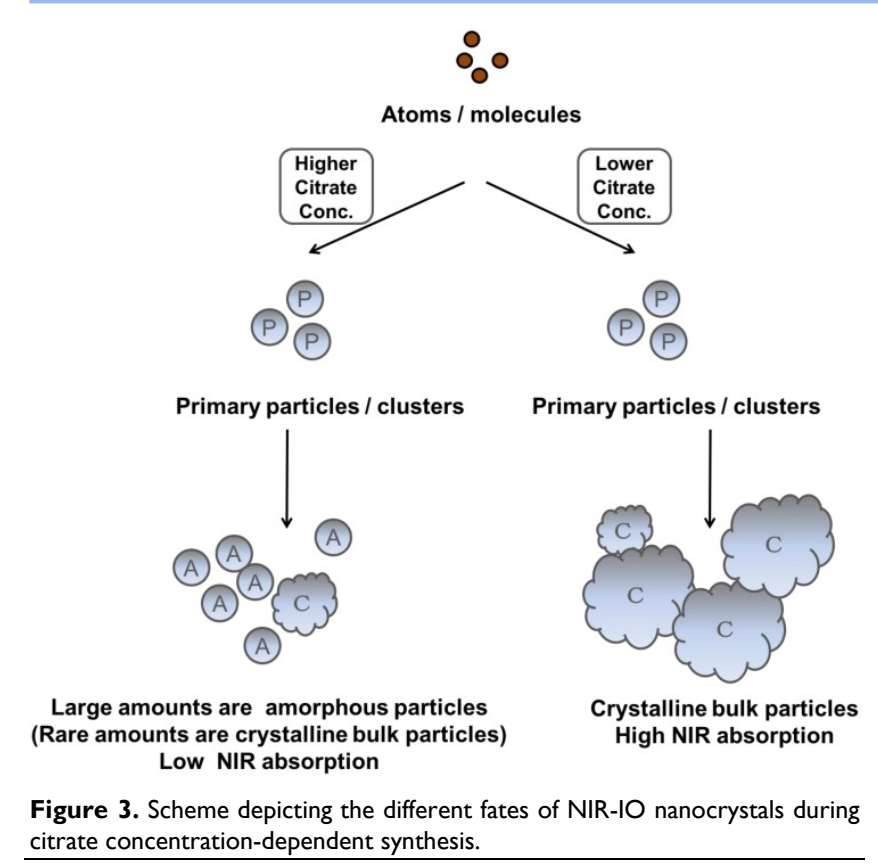

\subsection{Evaluation of the photothermal ability of NIR-IO nanocrystals}

NIR-IO nanocrystal revealed $182.7 \mathrm{~nm}$ in hydrodynamic size with PDI 0.252 in water solution and less than $5 \%$ variation in hydrodynamic diameter of NIR-IO nanocrystals was measured after 15 days. Similar results were oberved in PBS solution (Figure S3). To evaluate the photothermal effect, suspensions of NIR-IO nanocrystals prepared with different amounts of citrate were irradiated with 808 and 660 $\mathrm{nm}$ lasers $\left(0.2 \mathrm{~W} / \mathrm{cm}^{2}\right)$. Figure $4 \mathrm{~A}$ shows that irradiation at $660 \mathrm{~nm}$ (dashed lines) produced a slightly larger temperature increase than irradiation at $808 \mathrm{~nm}$ (solid lines). This difference was due to the larger transition probability of ${ }^{6} \mathrm{~A}_{1} \leftrightarrow{ }^{4} \mathrm{~T}_{2}$ of $\mathrm{Fe}^{+3}$ ions, shown by the fact that the $\varepsilon$ values were higher at 660 $\mathrm{nm}$ than at $808 \mathrm{~nm}$. However, for cancer therapy or other biomedical applications, longer irradiation wavelengths are preferred due to their better tissue penetration. Therefore, we further evaluated the photothermal ability of the particles using higher doses $\left(1.5 \mathrm{~W} / \mathrm{cm}^{2}\right)$ of $808-\mathrm{nm}$ laser irradiation. Water and CNT were used as controls and positive controls, respectively. As shown in Figure 4B, NIR-IO prepared with $0.022 \mathrm{~g}$ of citrate showed the highest temperature increase (from room temperature to $60^{\circ} \mathrm{C}$ ) with 808-nm irradiation, whereas no obvious temperature increase occurred in the water experimental group. Notably, a two-fold higher concentration of CNT at the same light dose only increased the temperature to $47^{\circ} \mathrm{C}$. This trend was also shown in the $\varepsilon$ values (Table 1); the $\varepsilon$ values of all the tested NIR-IO nanocrystals were higher than that of CNT $\left(13.51 \mathrm{M}^{-1}\right.$ $\left.\mathrm{cm}^{-1}\right)$. When the citrate amount during synthesis was increased to $0.11 \mathrm{~g}$, the highest temperature attained using the NIR-IO nanocrystals decreased from $60{ }^{\circ} \mathrm{C}$ to $35^{\circ} \mathrm{C}$. As shown in Table 1 , the $\varepsilon$ value of $75.63 \mathrm{M}^{-1}$ $\mathrm{cm}^{-1}$ for NIR-IO nanocrystals prepared with $0.11 \mathrm{~g}$ citrate was lower than the value of approximately 650 $\mathrm{M}^{-1} \mathrm{~cm}^{-1}$ found for crystals prepared with $0.022 \mathrm{~g}$ citrate. The photothermal conversion efficiency of the crystals was also investigated, as in previous reports[54, 55]; the details conversion efficiency are provided in the Supporting Information. The resulting estimate of the photothermal conversion efficiency of NIR-IO nanocrystals was $21.2 \%$. This value exceeds that of many materials currently used in PTT, such as indocyanine green (15.1\%)[56], commercial gold nanoshells (13\%)[57] and $\mathrm{Fe}_{3} \mathrm{O}_{4} @ \mathrm{Cu}_{2-\mathrm{x}} \mathrm{S}$ nanoparticles (16\%)[58], and it is comparable to that of $\mathrm{Cu}_{2-\mathrm{x}} \mathrm{Se}$ nanocrystals $(22 \%)$ [57], commercial gold nanorods (21\%)[57], fabricated $\mathrm{Fe}_{3} \mathrm{O}_{4}$ cluster-structured nanocrystals (20.8\%)[59], and polypyrrole-coated gold metal balls $(24 \%)[60]$. The NIR-IO nanocrystals also displayed rapid heating capability due to their high photothermal conversion efficiency $(41 \%)$, as indicated by the time required to reach $90 \%$ of their highest temperature. These results not only demonstrated that NIR-IO nanocrystals have more potential as a promising PTT agent than indocyanine systems but also showed that NIR-IO nanocrystals have an ability similar to that of gold nanorods to serve as PTT agents due to their similar photothermal conversion efficiency. In the evaluation of photostability of NIR-IO nanocrystals, the curves of temperature raising were no obvious change after seven repeated laser irradiation cycles (light dose of 1 cycle is $1 \mathrm{~W} \mathrm{~cm}^{-2}, 600 \mathrm{~s}$ ) (Figure $4 \mathrm{C}$ ). The results of TEM and absorption spectrum also showed no obvious change in the morphology and optical property of NIR-IO nanocrystals via seven cycles of laser on/off (Figure 4D). Photostable issue in several photothermal agents such as gold nanorods was previous reported. Zhou et al. showed the gold nanorods obvious decrease in the curves of temperature raising and optical property via laser irradiation with lower light dose ( 1 cycle is $0.38 \mathrm{~W}$ $\left.\mathrm{cm}^{-2}, 600 \mathrm{~s}\right)$. The morphology of gold nanorods also changed after laser irradiation [26]. Thus, our prepared NIR-IO nanocrystals have excellent photostability for biomedical applications.

Table 1. Molar extinction coefficient $(\varepsilon)$ values at wavelength of 808 and $660 \mathrm{~nm}$.

\begin{tabular}{|c|c|c|}
\hline Sample & $\varepsilon$-value of $808 \mathrm{~nm}\left[\mathrm{M}^{-1} \mathrm{~cm}^{-1}\right]$ & $\varepsilon$-value of $660 \mathrm{~nm}\left[\mathrm{M}^{-1} \mathrm{~cm}^{-1}\right]$ \\
\hline A- $0.0022 \mathrm{~g}$ & 673.13 & 1027.75 \\
\hline B- $0.022 \mathrm{~g}$ & 645.83 & 945.67 \\
\hline C- $0.11 \mathrm{~g}$ & 75.63 & 142.49 \\
\hline $\mathrm{D}-\mathrm{CNT}$ & 13.51 & 16.20 \\
\hline
\end{tabular}




\subsection{MRI evaluation of NIR-activated IO Nanocrystals}

The NIR-IO nanocrystals produced using different amounts of citrate were studied by vibrating sample magnetometry (VSM) at room temperature. The magnetic hysteresis loops (Figure S4A) revealed that the saturation magnetization of citrate- $0.11 \mathrm{~g}$, citrate- $0.022 \mathrm{~g}$, and citrate-0.0022 g was 7.2266, 61.350, and $34.29 \mathrm{emu} / \mathrm{g}$, respectively. This result indicates that the amount of citrate used in the synthesis of the particles also affects the magnetic properties of the particles, and the high saturation magnetization values of these three experimental groups indicates that the crystals have potential for use as an MR imaging reagent [61]. To evaluate the MR ability, we chose the citrate-0.022 $\mathrm{g}$ experimental group. In general, magnetic nanocrystals are larger secondary structural superparamagnetic $\mathrm{Fe}_{3} \mathrm{O}_{4}$ particles can be used as negative MR contrast agents due to their ability to shorten the spin-spin $\left(T_{2}\right)$ proton relaxation time, thereby causing signal reduction and enhancing the darkness in $T_{2}$-weighted images [62]. Figure S4B

\section{A}

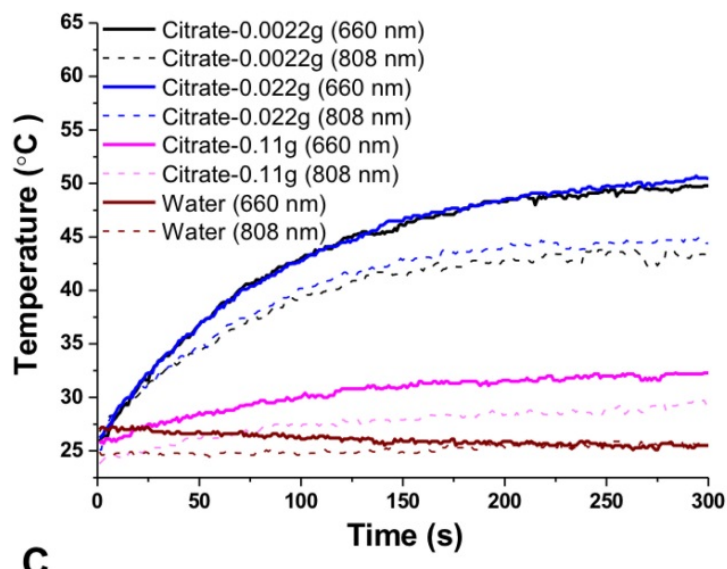

C

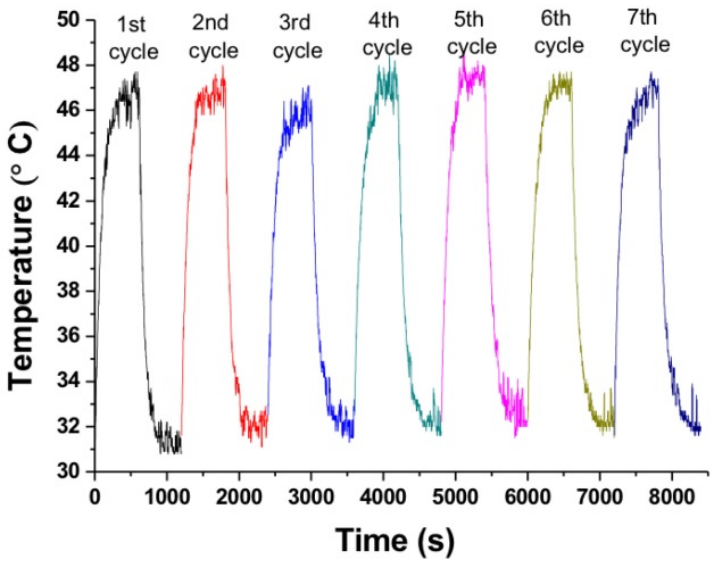

shows the inverse relaxation times $\left(1 / T_{2}\right)$ of the citrate- $0.022 \mathrm{~g}$ NIR-IO nanocrystals and commercial Resovist ${ }^{\circledR}$. The $T_{2}$ relaxation time of citrate- $0.022 \mathrm{~g}$ NIR-IO nanocrystals was not as good as that of Resovist $^{\circledR}$. The transverse relaxivity $\left(r_{2}\right)$ constant was calculated from the slopes of the relaxation rates of $1 / T_{2}$ plotted against Fe concentration. The $r_{2}$ values of the citrate-0.022 g NIR-IO nanocrystals and Resovist ${ }^{\circledR}$ were 141.40 and $240.51 \mathrm{~S}^{-1} \mathrm{mM}^{-1}$, respectively. Although these results indicate that Resovist $^{\circledR}$ has better $T_{2}$ MR imaging ability, the MR images with $0.022 \mathrm{~g}$ citrate NIR-IO nanocrystals were obtained on a $3 \mathrm{~T}$ clinical MR scanner. The results show that the NIR-IO nanocrystals produced a concentrationdependent decrease in the signal in the MR images (Figure S4C); additionally, the nanocrystals, like Resovist ${ }^{\circledR}$, could darken $T_{2}$-weighted MR images in a similar manner (Figure S4C). Thus, the NIR-IO nanocrystals of $0.022 \mathrm{~g}$ citrate group may have potential as a promising MR enhancement agent ( $T_{2}$-lowering ability).

\section{B}
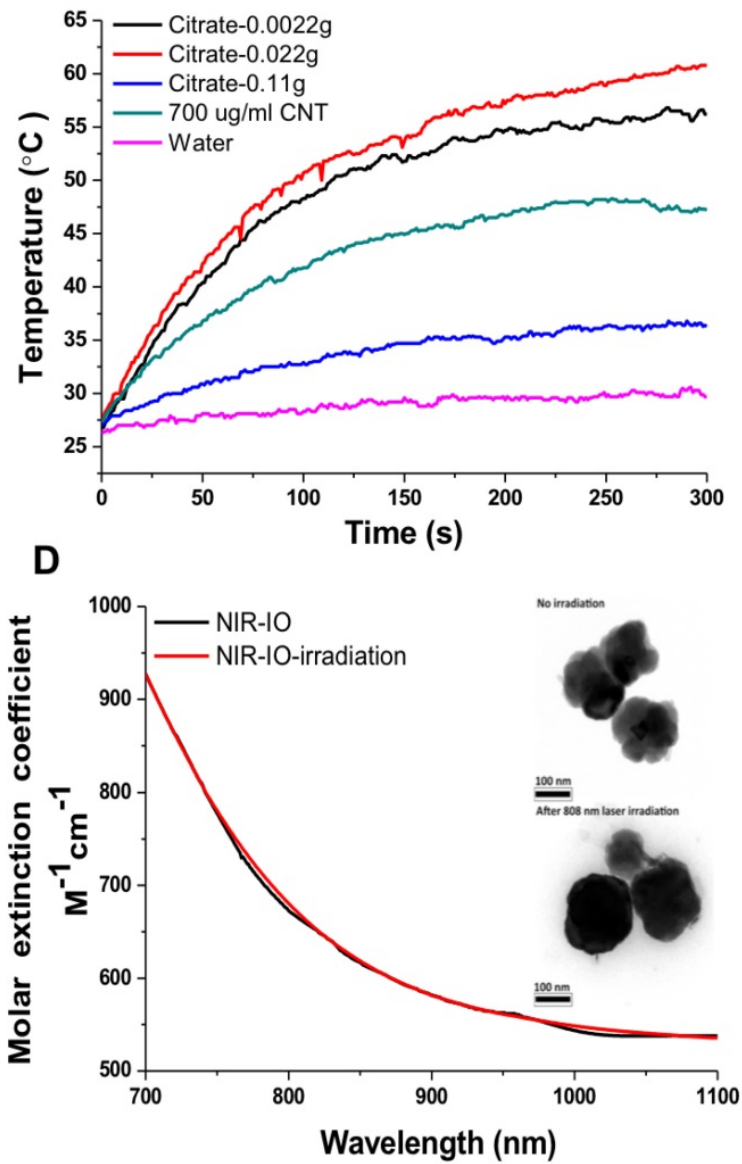

Figure 4. Photothermal effect of different types of NIR-IO nanocrystals after irradiation by 808 - and 660 -nm lasers. A) The laser power density (808/660 nm) was $0.2 \mathrm{~W} \mathrm{~cm}^{-2}$; B) the laser power density $(808 \mathrm{~nm})$ was $1.5 \mathrm{~W} \mathrm{~cm}-2$, and the concentrations of NIR-IO nanocrystals at the same Fe concentration $(350 \mu \mathrm{g} \mathrm{mL}-1)$. C) The heating curves of NIR-IO NCs with seven laser on/off cycles (1 cycle is $1 \mathrm{~W} \mathrm{~cm}-2,600 \mathrm{~s}$, and the concentrations of NIR-IO nanocrystals is $150 \mu \mathrm{mL}$-1); $\mathrm{D}$ ) Molar extinction coefficient - wavelength diagram and TEM image (insert) of NIR-IO nanocrystals with 808 nm laser irradiation or no irradiation. 


\subsection{In vitro photothermal effect and cell viability study}

To evaluate the photothermal effect and the toxicity of NIR-IO nanocrystals in vitro, HT-29 (human colorectal adenocarcinoma) cells were incubated with various concentrations of NIR-IO nanocrystals (prepared with $0.022 \mathrm{~g}$ of citrate) for $24 \mathrm{~h}$. The cellular uptake of the nanocrystals is shown in Figure S5. The dark field microscopy images indicate that after $24 \mathrm{~h}$ of incubation, large amounts of NIR-IO nanocrystals were taken up by HT-29 cancer cells and distributed in the cytoplasm (red arrows).

At specified times of incubation; the cells were exposed to an 808-nm laser at a power density of 1.5 $\mathrm{W} / \mathrm{cm}^{2}$ for $5 \mathrm{~min}$. The cell survival efficiency was then determined using the alamarBlue ${ }^{\circledR}$ assay. As shown in Figure 5A, under 808-nm laser irradiation, the temperature increments were concentration dependent; after $5 \mathrm{~min}$ of irradiation, the temperature reached approximately $51^{\circ} \mathrm{C}$. Quantitative evaluation of the results (Figure 5B) showed over $90 \%$ cell survivals when the cells were exposed to either NIR-IO nanocrystals or 808-nm laser irradiation alone. Significant phototoxicity of NIR-IO-treated cells was observed; after cells were exposed to $70 \mu \mathrm{g}$ $\mathrm{mL}^{-1}$ particles and 808-nm laser light irradiation for 5 min at a power density of $1.5 \mathrm{~W} / \mathrm{cm}^{2}$, the cell viability decreased to $25 \%$. These results show that the NIR-IO nanocrystals also possess excellent ability to convert NIR light to heat and to cause cell death after uptake into the cell. The increased cell viability in the group exposed to NIR-IO nanocrystals might have been caused by the availability of additional free iron released from the NIR-IO nanocrystals in the cells, which may have increased the cellular metabolic activity [63].
A

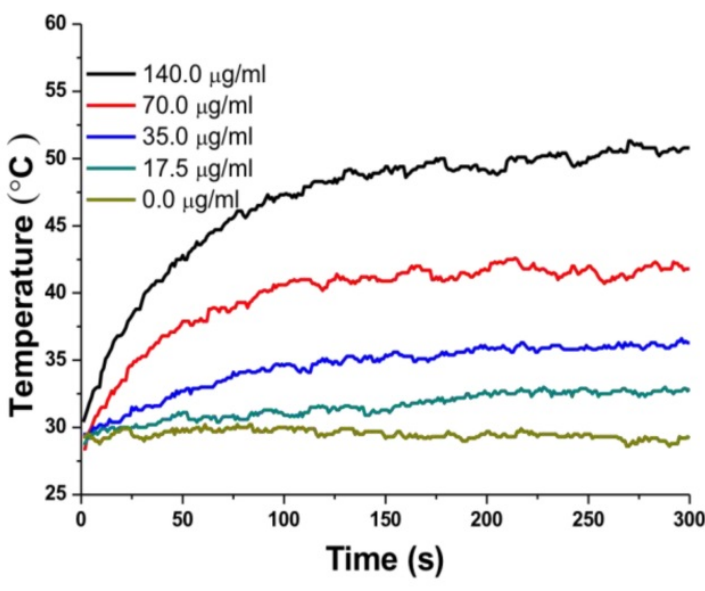

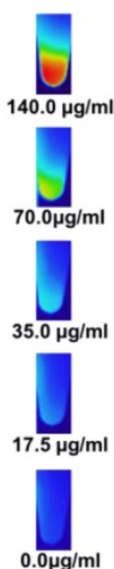

B

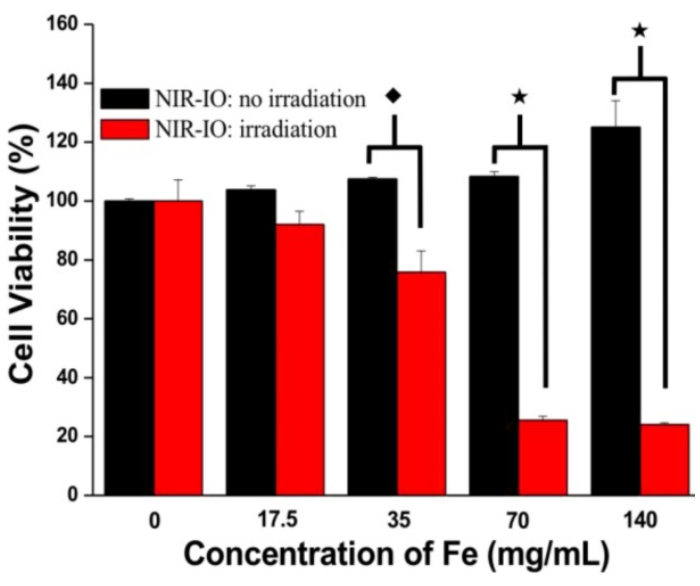

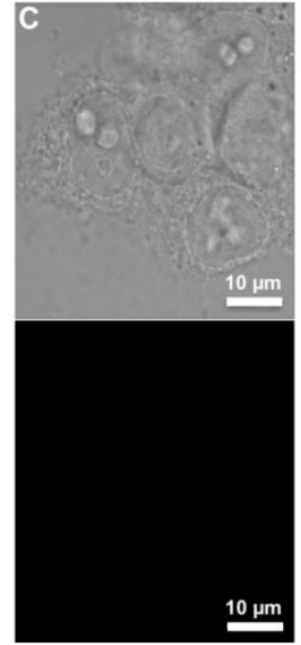
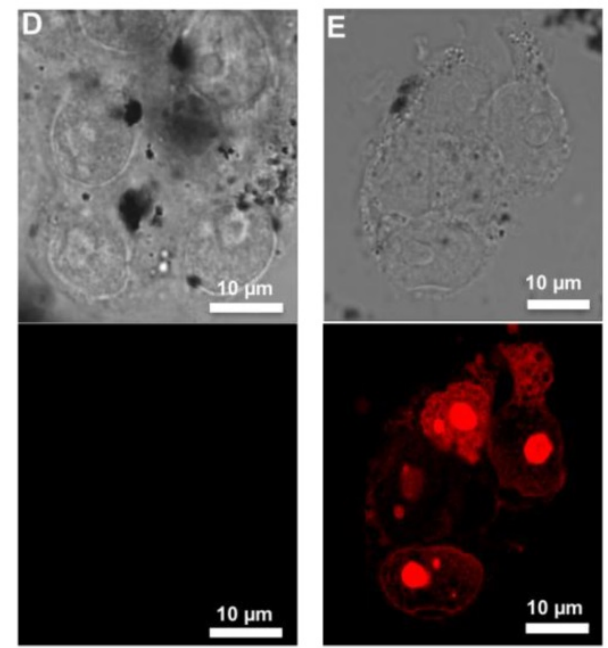

Figure 5. A) Heating curves of HT-29 cancer cells treated with NIR-IO nanocrystals at various Fe concentrations as a function of irradiation time using 808 -nm laser irradiation (the power density was $1.5 \mathrm{~W} \mathrm{~cm}^{-2}$ ). B) Cell viability of HT-29 cancer cells incubated with NIR-IO nanocrystals at various Fe concentrations. (D) Significant difference between the group of NIR-IO irradiation and the group of NIR-IO no irradiation $(p<0.001)$. ( $\$)$ Significant difference between the group of NIR-IO irradiation and the group of NIR-IO no irradiation $(p<0.05) ; n=3$. Confocal laser scanning microscopy images of HT-29 cancer cells treated with C) PBS $+808-n m$ laser irradiation, D) NIR-IO nanocrystals and E) NIR-IO nanocrystals + 808-nm laser irradiation at a power density of $1.5 \mathrm{~W} \mathrm{~cm}^{-2}$. The cells were stained with PI. The Fe concentration of the NIR-IO nanocrystals was $140 \mu \mathrm{g} \mathrm{mL}-1$. 
Photothermally treated cells were stained with propidium iodide (PI) for further investigation of the photothermal effects of the NIR-IO nanocrystals in HT-29 cells. The confocal microscopy images in Figure 5C showed that most of the cells treated with PBS plus laser irradiation retained a healthy appearance, and no red fluorescence of the PI dye was detected in the cells treated with NIR-IO nanocrystals and without laser irradiation (Figure 5D). Cells treated with NIR-IO nanocrystals with 808-nm laser $\left(1.5 \mathrm{~W} \mathrm{~cm}^{-2}\right)$ light exposure for $5 \mathrm{~min}$ revealed PI fluorescence accumulation in the nuclei, indicating cell membrane disruption and necrotic reactions with PTT effects (Figure 5E). The major cause of necrosis of the cells treated in this manner has been shown to be rapid heating and increased duration of heat shock.[64] For example, higher laser power intensity irradiation produces rapid heating, causing the cell to lose its membrane integrity. Thus, our results also provide evidence concerning the photothermal effects of the NIR-IO nanocrystals taken up by cancer cells; upon laser exposure, cell structures were seriously damaged due to the rapid temperature increase caused by the excellent heat generation of the particles, causing the cells to undergo necrosis instead of apoptosis [38].

\subsection{In vitro biochemical investigation after photothermal therapy}

Although our investigation of the cell responses to the photothermal effect was complete, the biomolecular alterations in the treated cells were still unclear. Therefore, we used synchrotron-based infrared microspectroscopy (SR-IMS), an ultra-high spatial resolution technique, to evaluate possible alterations in biomolecules [65].

To investigate biochemical alterations in the NIR-IO-treated cancer cells, we first scanned the IR spectrum of HT-29 cancer cells in the mid-infrared range $\left(3600-950 \mathrm{~cm}^{-1}\right)$. The entire range of the spectrum is shown in Figure S6A. Figure S6B-D compares the FT-IR spectrum of HT-29 cancer cells with that of HT-29 cancer cells that given NIR-IO-mediated PTT in the three spectral regions of $3000-2800 \mathrm{~cm}^{-1}$ (signals from lipids), $1700-1450 \mathrm{~cm}^{-1}$ (signals from amide I and II), and 1300-900 $\mathrm{cm}^{-1}$ (signals from DNA/RNA and glycogen). There are differences in the spectral regions corresponding to lipids and to amide I and II. The mapping images shown in Figure S7 not only provide information on the distribution of these biomolecules in the cell but also show the differences in cell morphology caused by NIR-IO PTT. These results could reflect the alteration of biomolecules in HT-29 cancer cells. In summary, our preliminary results showed that
NIR-IO-treated cells underwent changes corresponding to the signal of the lipid and amide I and II regions compared with untreated cells; however, there were no obvious variations in the DNA/RNA or glycogen regions of the treated cells.

The mechanisms of cell death undergo necrosis and apoptosis after PTTtreatments has been reported [66]. The apoptosis pathway involves lysosomal membrane permeabilization followed by the release of cathepsins into the cytosol. The cathepsins cleave Bid and trigger the intrinsic pathway of apoptosis. Although apoptotic cells can be transformed into necrotic cells via secondary necrosis[67], the investigation of the molecular mechanism of cell death remains an important issue in the clinical development of PTT. Pino et al. indicated that the PTT should consider the parameters (nanoparticle type, dosage, and heating capacity) needed to produce maximal apoptosis of cancer cells and thereby achieve high efficacy treatment. In our case, we also observed that NIR-IO nanocrystals were able to permeabilize the lysosomal membrane after low-intensity $(0.8 \mathrm{~W}$ $\mathrm{cm}^{-2}$ ) 808-nm laser irradiation (data not shown). However, we chose to use high-intensity laser irradiation because of the decrease in the drug uptake into cells in an in vivo environment and the attenuation of the light intensity in the treated tissue.

To further study these interesting variations after NIR-IO treatment, we performed peak deconvolution of the lipid and amide I and II signals.[68] The upper part of Figure 6 shows the region of the signal corresponding to symmetric and asymmetric stretch of $-\mathrm{CH}_{2}$ or $-\mathrm{CH}_{3}$; the signal ratios of symmetric and asymmetric $-\mathrm{CH}_{3} /-\mathrm{CH}_{2}$ also show obvious enhancement after NIR-IO-mediated PTT. Although the $-\mathrm{CH}_{3}$ and $-\mathrm{CH}_{2}$ signals usually indicate lipid content $[69,70]$, the $-\mathrm{CH}_{3}$ signal also has another meaning in this experiment. The $-\mathrm{CH}_{3}$ lipid signal had a smaller contribution than the $-\mathrm{CH}_{2}$ lipid signal. The $-\mathrm{CH}_{3}$ signal also provides information about the protein content of cells, which may change when cells experience stress. Therefore, the observed $-\mathrm{CH}_{3}$ signal increase after PTT may be indirect evidence that the intracellular protein content increased due to the production of heat shock proteins. As many studies have indicated, heat shock proteins (HSPs) such as HSP70 and HSP90 are generated when cells are exposed to high temperature $\left(\geq 43^{\circ} \mathrm{C}\right)$. [69, 71-73] The investigation of the amide I and II signal region (Figure 6, lower part) showed that the intracellular protein content was altered. This phenomenon might be caused by the generation of numerous HSPs, resulting in alterations in intracellular protein secondary structure [74]. Another possibility is that the high temperature condition caused a-helix 
unfolding while allowing $\beta$-sheets to remain intact [75]. However, to produce a complete loss of secondary structure, the cells would need to reach a very high temperature (above $60{ }^{\circ} \mathrm{C}$ ); this is likely why some of the a-helix signal remained after PTT [76]. These results provide evidence regarding the intracellular biochemical condition and indicate that proteins underwent alterations after cells were exposed to PTT.

\subsection{In vivo performance of NIR-IO nanocrystals via intratumor injection}

Before moving forward to investigate magnetic, in vivo, tumor-targeting photothermal therapy using NIR-IO nanocrystals, we first tested the photothermal properties of the nanocrystals by intratumor injection. The spatial temperature distribution in the tumor area during NIR-IO nanocrystal-mediated PTT was measured using a thermographic camera. The body temperature of the mice prior to PTT was approximately $32{ }^{\circ} \mathrm{C}$, and the temperature of the tumor area after exposure to an $808-\mathrm{nm}$ laser at a power density of $1.5 \mathrm{~W} \mathrm{~cm}^{-2}$ for $10 \mathrm{~min}$ with or without intratumoral injection of phosphate buffered saline (PBS) approached $38^{\circ} \mathrm{C}$ (data not shown). The temperature alteration after intratumoral injection of the clinical Resovist ${ }^{\circledR}$ agent was also investigated (Figure S8, A-B); the results showed only a slight elevation in temperature $\left(32\right.$ to $\left.40{ }^{\circ} \mathrm{C}\right)$. However, the tumor that was intratumorally injected with NIR-IO nanocrystals (7 $\mathrm{mg}$ of $\mathrm{Fe}$ per animal) and then exposed to an 808-nm laser exhibited an excellent temperature increase from 32 to $56{ }^{\circ} \mathrm{C}$ (Figure S8, A-B). Histological analysis of the tumor tissue provided further evidence of the tumor cell responses to the high temperature. As shown in Figure S8C, examination of H\&E-stained tissue sections demonstrated differences in tissue morphology in the tumors of the NIR-IO and Resovist ${ }^{\circledR}$ groups 4 days after laser irradiation. In the NIR-IO group, the cells in the tumor tissue were shrunken and displayed no nuclei, whereas in the group treated with Resovist ${ }^{\circledR}$, the tissues exhibited normally organized cellular structure.
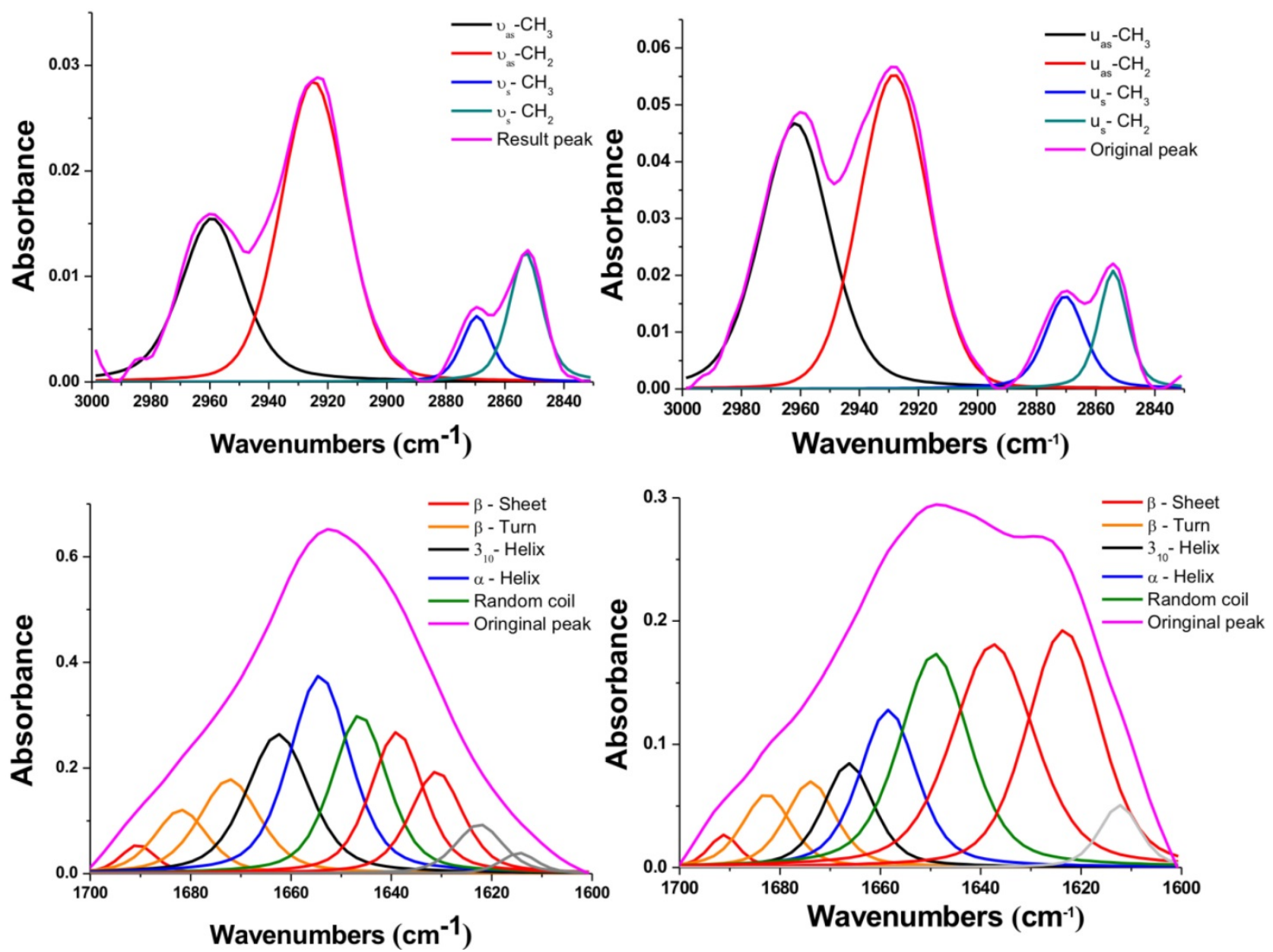

Figure 6. FTIR spectra of HT-29 cancer cells treated with NIR-IO nanocrystals (left) and of cells treated with NIR-IO nanocrystals +808 -nm laser irradiation (right); deconvolution analysis and Voigt peak fitting were performed in accordance with the literature. 
In addition, a $7 \mathrm{~T}$ MRI instrument was used for an in vivo evaluation of the MR imaging of the tumor site in a mouse that was intratumorally injected with NIR-IO nanocrystals. As shown in Figure S9, the post-injection site (1.530 target pixel / background pixel, gray arrow) presented obviously darkened $T_{2}$-weighted MR images compared with the same tumor prior to injection (8.435 target pixel / background pixel). These results indicate that our material provided an efficient basis for PTT and MR imaging even in vivo. However, in clinical cancer therapy, improving drug accumulation and achieving more efficient therapy via intravenous injection are always important. Therefore, it will be necessary to verify the theranostic efficacy and to investigate the photothermal damage that occurs in tissues after intravenous injection of NIR-IO nanocrystals.

\subsection{In vivo magnetically targeted photothermal therapy and its efficacy evluation}

Because our preliminary in vivo data revealed the high NIR-mediated photothermal efficiency of NIR-IO nanocrystals and their good ability to enhance MR imaging, we performed magnetically targeted PTT treatment via intravenous injection using the HT-29 tumor model in nude mice. The tumor-bearing mice were divided into five groups: PBS; PBS + 808-nm laser irradiation; NIR-IO + MF targeting; NIR-IO + 808-nm laser irradiation; and NIR-IO + MF targeting +808 -nm laser irradiation followed by intravenous injection of $100 \mu \mathrm{L}$ of NIR-IO nanocrystals ( $9.5 \mathrm{mg} \mathrm{mL}^{-1}$ of $\mathrm{Fe}$ ) and PBS. A magnet was used to magnetically target each tumor for $24 \mathrm{~h}$. After magnetic targeting, the tumors with or without exposure to an 808-nm laser at a power density of 1.5 $\mathrm{W} \mathrm{cm}-2$ for $10 \mathrm{~min}$ were measured. As shown in Figure 7 (A-D), the spatial temperature distribution at the tumor surface in the MF and non-MF groups was increased to $53^{\circ} \mathrm{C}$ and $43^{\circ} \mathrm{C}$, respectively. In contrast, the temperature at the tumor surface of the control group (intravenously injected PBS) remained below $32{ }^{\circ} \mathrm{C}$ during irradiation. Within 15 days, the tumor volumes in the NIR-IO + MF targeting + 808-nm laser irradiation group decreased from $183.1 \pm 18.2 \mathrm{~mm}^{3}$ to $121.6 \pm 45.4 \mathrm{~mm}^{3}$ (tumor growth inhibition, TGI\% = 83.1) (Figure 7E). The tumor volumes in these animals were significantly smaller than those of the NIR-IO + $808 \mathrm{~nm}(\mathrm{TGI} \%=56.8, p<0.05)$ and NIR-IO $+\mathrm{MF}$ groups $(p<0.001)$. No significant differences in tumor volume were found among the NIR-IO $+808 \mathrm{~nm}$, PBS and PBS $+808-n m$ laser irradiation groups. Figure 7F shows the relative weight curves of the experimental mice. The weight differences among the five groups were similar, and no apparent weight loss was observed during the experimental period. In recent clinical cancer treatments, the method of achieving drug accumulation in the tumor has been particularly important for determining the treatment conditions (i.e., better accumulation could decrease the effective treatment dosage and also reduce side effects). Herein, as our results show, NIR-IO nanocrystals represent a potentially promising treatment because they not only displayed good magnetic tumor targeting ability but also produced an excellent photothermal ablation effect. Figure S10 shows photos of mice after NIR-IO treatments. One day after irradiation, the irradiation site on the side of the tumor displayed skin burns (Figure S10, middle panel). Four days later, a large eschar was found in the MF experimental group on the tumor side; small or no areas of eschar were found on the sides of the tumors in the non-MF and PBS-treated experimental group, respectively (Figure S10, right panel). Eight days after irradiation, the tumors of mice receiving NIR-IO treatment with MF and irradiation showed great tumor growth inhibition, whereas the tumors without irradiation or those in the NIR-IO treatment experimental group continued to grow uninhibited.

To further demonstrate the occurrence of photothermal damage in tumor tissue, histological methods were used 15 days after irradiation. Hematoxylin and eosin (H\&E) staining of tumor tissues from the NIR-IO + MF group showed many necrotic cells that were stained by eosin, and pyknosis was also observed in the tumor tissue. The PBS group showed tumor cells with normally organized cellular structures and pleomorphic nuclei (Figure 7G). These results indicate that NIR-IO nanocrystals possess excellent ability to cause photothermal damage and cause tumor cells to undergo necrosis or apoptosis. Although photothermal damage to the tumor was clearly observed, no noticeable sign of organ damage or inflammatory lesion was observed in either the treated or untreated groups (Figure 7G). Thus, NIR-IO nanocrystal revealed high biocompatibility without irradiation and excellent PTT efficacy in irradiated area. For the evaluation of MR imaging ability via intravenous injection, NIR-IO treatment group was obviously darken than other groups in tumor region (Figure S11 and Figure 8). T2-weighted MR image of NIR-IO nanocrystals of plus magnetic targeting treatment (1.220 target pixel / background pixel) was 4.8-fold darked area in tumor area compared with that in commercial Resovist ${ }^{\circledR}$ plus magnetic targeting treatment group (5.902 target pixel). Biodistribution of NIR-IO nanocrystals were also evaluated after $24 \mathrm{~h}$ intravenous postinjection. As shown in Figure 8C, similar tissue accumulation phenonmena were observed in Resovist ${ }^{\circledR}$ and NIR-IO without MF targeting groups. NIR-IO nanocrtystals revealed 
significatly increased tumor accumulation and decreased liver accumulation with MF application. It is noticed that more than 4-fold higher accumulation in NIR-IO with MF targeting group were observed than in other three groups (NIR-IO without MF targeting or Resovist ${ }^{\circledR}$ withour or with MF targeting groups). MF applications for increased tumor accumulation were utilized in magnetic nanocarriers. Zhang et al. designed the doxorubicin (DOX)-loaded hollow mesoporous CuS nanoparticles (HMCuS NPs) with superparamagnetic IO nanoparticles for chemo-phototherapy and 1.5-fold increment were observed in biodistribution results after MF targeting [77] Qian et al. reported the theranostic nanocapsules made by PCLA-PEG-PCLA polymers hierarchically assembling SPIOs, IR820 and a chemotherapeutic agent for tumor theranostics and 2-fold accumulation increment were observed in tumor area after MF targeting [78] Dong et al. was prepared magnetic mesoporous silica nanoparticles for cancer gene therapy. The biodistribution results showed that 1.5-fold enhancement in the tumor were observed via MF targeting strategy [79] Guo et al. developed MF targeting strategy via IO nanoparticles and 1.94-fold increments of tumor accumulation were observed with MF targeting [80]. Our prepared NIR-IO nanocrystals revealed not only excellent PTT efficacy bit also more than 4-fold enhancement in tumor accumulation with MF targeting strategy. The reduced liver accumulation in NIR-IO with MF tageting group also support our prepared NIR-IO nanocrystals for cancer theranostics (Figure 8C). Krishnan et al. reported detail situations such as blood clearance pharmacokinetics, biodistribution studies with size effect, and metabolic pathway of $\mathrm{IO}$ nanoparticles in living body.[81] We proposed that our prepared NIR-IO nanocrystals may form the protein-nanocrystal complex in the circulation and results in higher accumulation in spleen/liver and lower accumulation in kidney (Figure 8C). Aforementioned situations would cause by mechanical filtration of macrophage phagocytosis in spleen [81, 82]. The fate of liver accumulations of NIR-IO nanocrystals would result in the cellular uptake by Kuppffer cells and then iron-based nanocrystals would be lysed in acidic organelles such as lysosomes. The similar mechanism would happen in spleen accumulation; however, the degradation rate via macrophages was slower in spleen than Kupffer cells in liver tissue due to the less iron storage proteins presence in the spleen. In addition, the injection dose would also influence on the degradation rate. Wei et al. reported that the metabolism of high dose IONPs $\left(8.4 \mathrm{mg} \mathrm{kg}^{-1}\right)$ needed near three weeks for degradation.[83] Thus, we speculated that our prepared NIR-IO nanocrystals may need more than one month for degradation. Recently, some researchers reported that the IONPs would cause inflammatory factors such as IL series or TNF- $\alpha$, however no obvious tissue toxicity was observed in the spleen [84]. We also investigated the relationship of tumor accumulation of NIR-IO nanocrystals and its photothermal efficacy in vitro and in vivo. The photothermal profile of NIR-IO + MF targeting with laser irradiation in vivo (Fig. 7A) is similar as that of $140 \mu \mathrm{g} / \mathrm{ml}$ NIR-IO nanocrystal in vitro (Fig. 5A) that may due to the PTT efficacy from similar concentration of NIR-IO.

The use of optical nanocrystals that absorb light at NIR wavelengths followed by conversion of the absorbed energy to heat have attracted much interest as a means of modulating phototreatment in deep tissues with relatively low absorption/ scattering at $\lambda=650-900 \mathrm{~nm}$. This photothermal conversion process potentially minimizes thermal injury to the surrounding tissues.[66, 67] NIR IO nanocrystals display a promising combination of optical and magnetic features in a single $\mathrm{Fe}-\mathrm{O}$ compound, making their optical application easy to integrate with magnetically targeted accumulation in the area of interest. Some very recent studies have examined photothermal cancer therapy using IO nanocrystals. As shown in Table 2, Chu et al. used co-precipitation synthesis to prepare $\mathrm{Fe}_{3} \mathrm{O}_{4}$ nanoparticles that were used in PTA in tumor-bearing mice[39], Espinosa et al. used the thermal decomposition method to prepare $\mathrm{Fe}_{3} \mathrm{O}_{4}$ nanoparticles with a low light dose $\left(180 \mathrm{~J} \mathrm{~cm}^{-2}\right)$ as a PTT agent[85], and Shen et al. designed a cluster of $\mathrm{Fe}_{3} \mathrm{O}_{4}$ nanoparticles that were used at a low injection dosage against A549 tumors [86]. However, the above-mentioned studies evaluated the PTT efficacy using the intratumoral injection model. Therefore, these evaluations are limited in their clinical application. In addition, Zhou et al. designed $\mathrm{Fe} / \mathrm{Fe}_{3} \mathrm{O}_{4}$ nanoparticles (1460 mg [Fe] kg-1 body weight) to be used against HeLa tumors. This research used an MF targeting strategy to achieve higher $\mathrm{Fe} / \mathrm{Fe}_{3} \mathrm{O}_{4}$ nanoparticle accumulation in tumors, achieving enhanced MR contrast images and excellent therapy efficacy after 808-nm laser $\left(93 \mathrm{~J} \mathrm{~cm}^{-2}\right)$ irradiation for 14 days [26] Chen et al. used the thermal decomposition method to synthesize $\mathrm{Fe}_{3} \mathrm{O}_{4}$ nanocrystals with high lattice orientation along the (400) and (440) planes. The animal experimental results showed that these nanocrystals yielded promising PTT efficacy at a dosage of $20 \mathrm{mg}$ [Fe] $\mathrm{kg}^{-1}$ body weight and a light dose of $1500 \mathrm{~J} \mathrm{~cm}^{-2}$.[49] Ren et al. reported the red blood cell-derived membrane vesicles for $\mathrm{Fe}_{3} \mathrm{O}_{4}$ nanoparticles encapsulation and 
their in vivo results showed that PTT efficacy at a dosage of $2.5 \mathrm{mg}$ [Fe] $\mathrm{kg}^{-1}$ body weight with a light dose of $1500 \mathrm{~J} \mathrm{~cm}^{-2}$ [87] Yang et al. also evaluated PTT effects of hyaluronan-modified IONPs at adosage $20 \mathrm{mg}$ [Fe] $\mathrm{kg}^{-1}$ body weight with a light dose of $1200 \mathrm{~J} \mathrm{~cm}^{-2}$ [88]. Although the above-mentioned studies displayed several advantages in PTT efficacy, some limitations (i.e., in treatment too high doses or light dose) were also raised in these studies. Notably, Shen et al. provided a hydrothermal method to synthesize $\mathrm{Fe}_{3} \mathrm{O}_{4}$ nanoparticles with high biocompatibility and stability and these $\mathrm{Fe}_{3} \mathrm{O}_{4}$ nanoparticles showed not only great enhancement of MR contrast images (70-100 mg [Fe] $\mathrm{kg}^{-1}$ body weight) but also good PTA ability (450 J $\mathrm{cm}^{-2}$ ) via MF targeting.[38] Although they did not directly clarify the mechanisms for the NIR absorption ability, the synthesis process indirectly provided evidence for a relationship between the ligand-assisted synthesis approach and NIR absorption features. Additionally, Guo et al. used different size of IO nanoparticles prepared by hydrothermal method for in vivo PTT efficacy; however the multiple procedure of PTT (drug injection at days 0, 3, 6 and laser irradiation at 1, 4,7) was not easy to be carried out in clinical studies.[53] Recently, ferroptosis is a new pathway of iron-related cell death [89] [90]. It is also reported that the median lethal dose (LD-50) of IO nanoparticles was 300-600 $\mathrm{mg}[\mathrm{Fe}] \mathrm{kg}^{-1}$ [81]. Thus, we used the less dosage of NIR-IO (38 mg [Fe] $\mathrm{kg}^{-1}$ ) in this study that is superior biocompatibility and more safety for further biomedical applications.

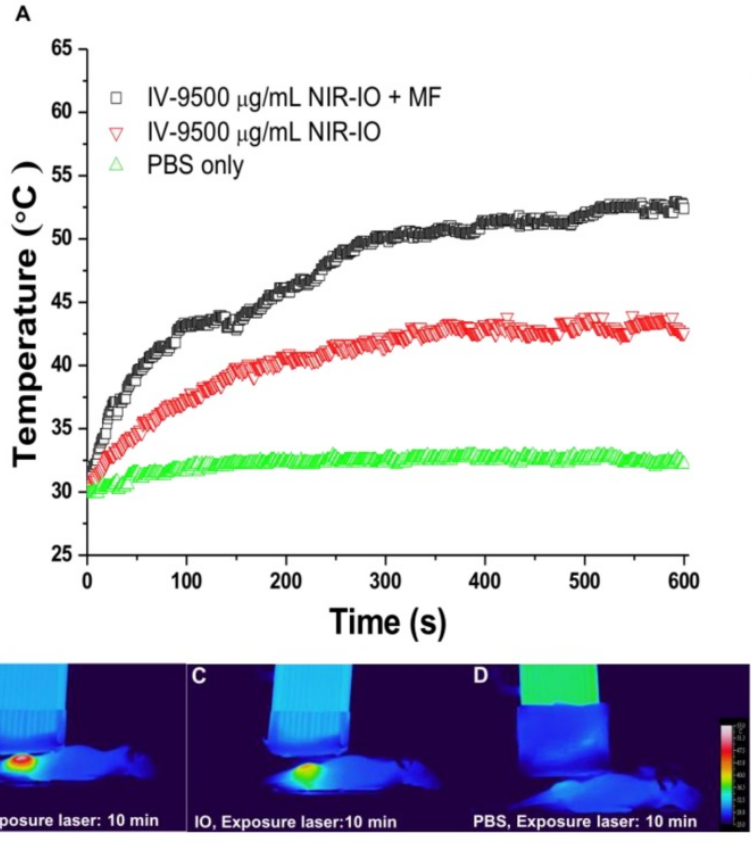

G

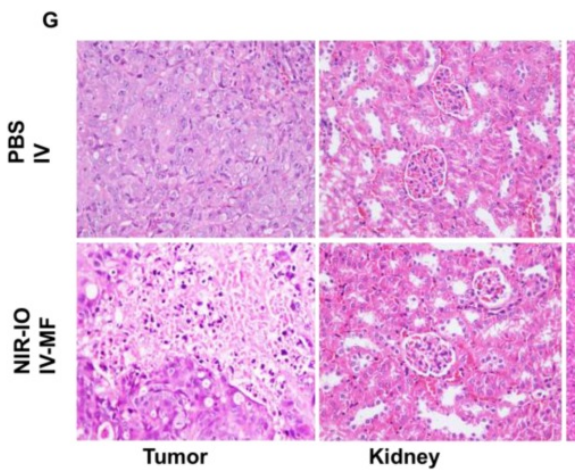

E

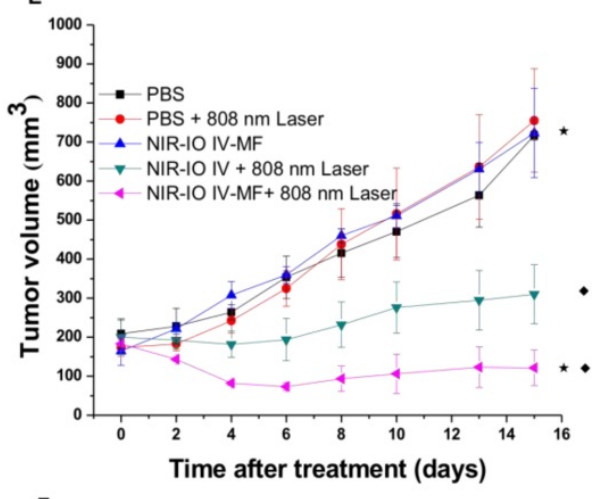

$\mathbf{F}$

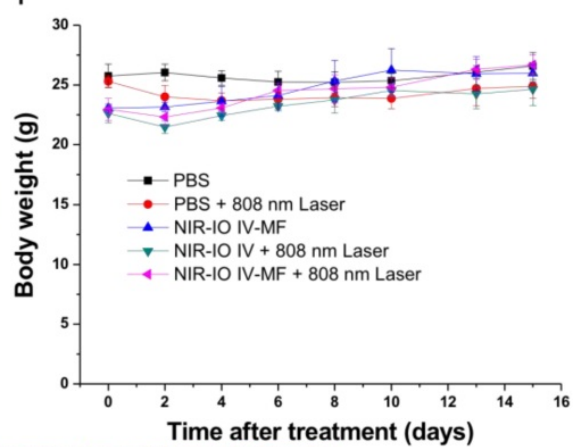

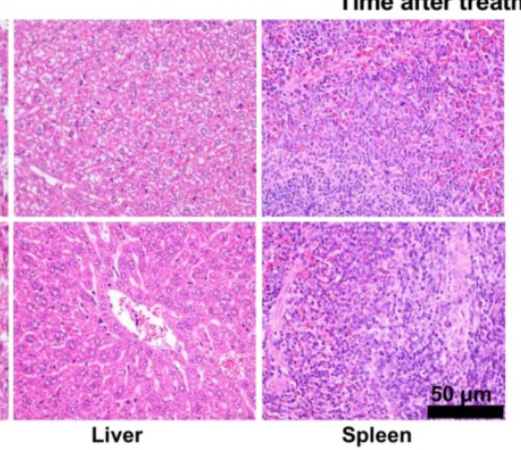

Figure 7. A) Heating curves; B-D) thermographic images of mice bearing HT-29 tumors that had been IV injected with PBS and NIR-IO nanocrystals ( 38 mg kg-1) after 10-min exposure to 808-nm laser irradiation (1.5 W cm-2) and MF targeting. E) Tumor growth, F) relative weight curves and G) H\&E-stained images of HT-29 tumors in nude mice after PTT treatment. The data are presented as the mean \pm standard deviation (SD). ( $\square$ ) Significant difference between the group of NIR-IO IV-MF + $808 \mathrm{~nm}$ laser and the PBS group $(p<0.001)$. ( $\diamond)$ Significant difference between the group of NIR-IO IV-MF + 808nm laser and the group of NIR-IO IV + 808nm laser $(p<0.05) ; \mathrm{n}=3$. The Fe concentration of the intravenously injected NIR-IO nanocrystals was $38 \mathrm{mg} \mathrm{kg}^{-1}$, and the $808-\mathrm{nm}$ laser $\left(1.5 \mathrm{~W} \mathrm{~cm}^{-2}\right)$ irradiation time was 10 min. 
Table 2. Efficacy comparison of photothermal cancer therapy studies that using iron oxide

\begin{tabular}{|c|c|c|c|c|c|c|c|}
\hline Sample & $\begin{array}{l}\text { Size / PTT conversion } \\
\text { efficiency }(\mathrm{nm}) /(\%)\end{array}$ & $\begin{array}{l}\text { Injection } \\
\text { model }\end{array}$ & $\begin{array}{l}\text { [Fe] injection } \\
\left(\mathrm{mg} \mathrm{kg}^{-1}\right)\end{array}$ & $\begin{array}{l}\text { Irradiation wavelength } \\
(\mathrm{nm})\end{array}$ & $\begin{array}{l}\text { Light Dose } \\
\left(\mathrm{J} \mathrm{cm}^{-2}\right)\end{array}$ & $\begin{array}{c}\Delta \mathrm{T} \text { Heating } \\
\text { Temperature }\left({ }^{\circ} \mathrm{C}\right)\end{array}$ & Ref \\
\hline $\mathrm{Fe}_{3} \mathrm{O}_{4} / \mathrm{DSPE}-\mathrm{PEG}$ & 10 / not offered & I.T & $20-25$ & 808 & 300 (1/24 Days) & not offered & 38 \\
\hline $\mathrm{Fe}_{3} \mathrm{O}_{4}$ clusters of NPs & 225 / not offered & I.T & 2.5 & 808 & 900 & 22 & 72 \\
\hline $\mathrm{Fe}_{3} \mathrm{O}_{4} \mathrm{NCs}$ & 20 / not offered & I.T & 35 & 808 & 180 & 15 & 71 \\
\hline HCIONPs & 15 / not offered & I.V & 20 & 885 & 1500 & 25 & 47 \\
\hline $\mathrm{Fe} / \mathrm{Fe}_{3} \mathrm{O}_{4}$ & $13 / 20.3$ & I.V & 1460 & 808 & 93 (1/14 Days) & 12 & 25 \\
\hline $\mathrm{Fe}_{3} \mathrm{O}_{4} @ \mathrm{CMCTS}$ & 177 / not offered & I.V & $70-100$ & 808 & 450 & 22 & 37 \\
\hline $\mathrm{Fe}_{3} \mathrm{O}_{4}-310 \mathrm{~nm}$ & 310 / not offered & I.V & 40 (1/3 Dose) & 808 & 270 (1/3 Days) & 20 & 75 \\
\hline MNC@RBCs & 200 / not offered & I.V & 2.5 & 808 & 1500 & 12 & 73 \\
\hline HA-SPIONs & $20 /$ not offered & I.V & 20 & 808 & 1200 & not offered & 74 \\
\hline NIR-IO (ours) & $156 / 21$ & I.V & 38 & 808 & 900 & 22 & \\
\hline
\end{tabular}
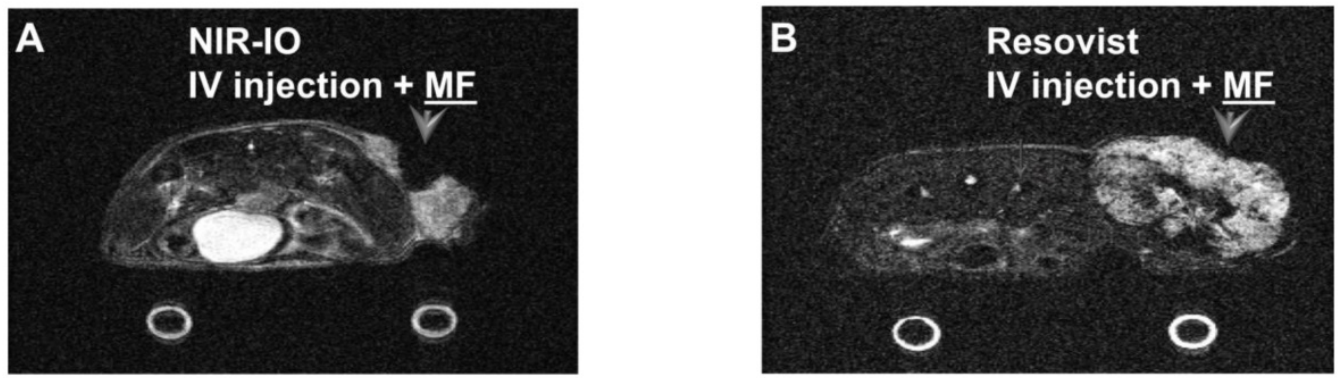

C

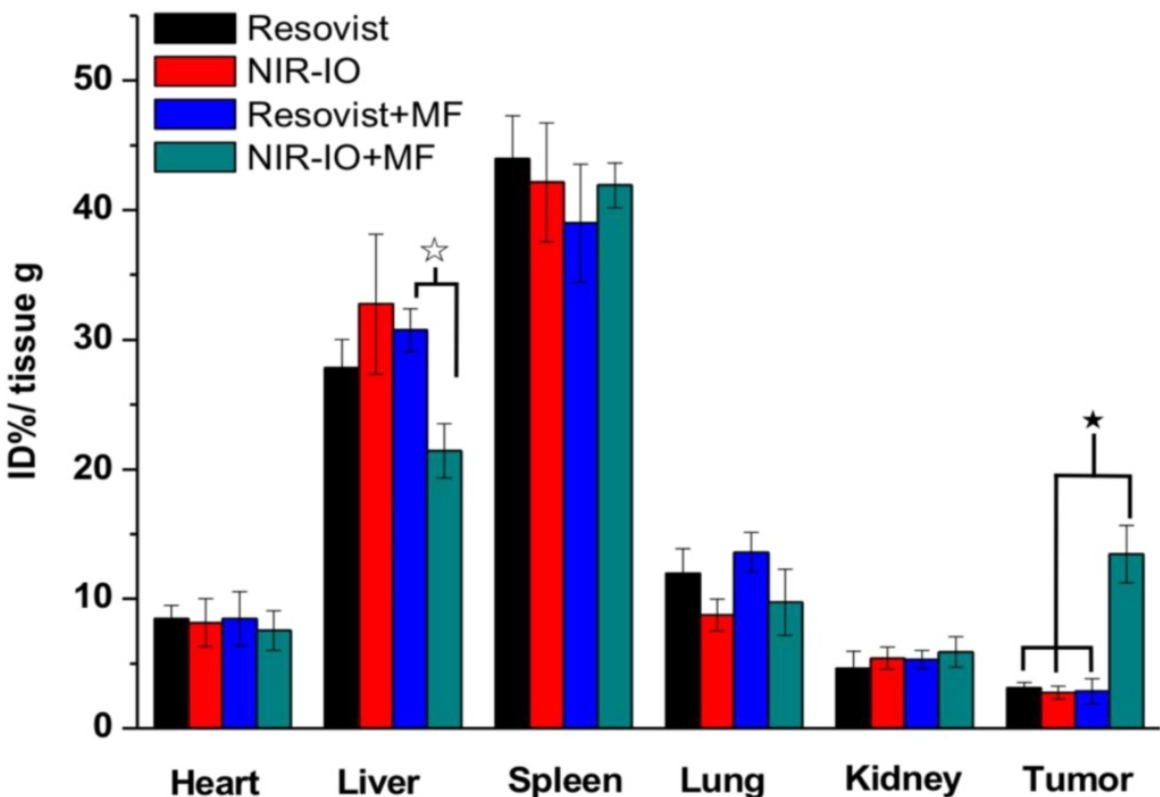

Figure 8. MR imaging of mice treated with A) NIR-IO nanocrystals or B) Resovist ${ }^{\circledR}$ and subjected to MF targeting. In both cases, the Fe concentration was 18 mg kg-1. C) Biodistribution of iron amount in tumors and other organs. The data are presented as the mean \pm standard deviation (SD). ( $\star$ ) Significant difference in tumors between the group of NIR-IO+MF and orther groups such as Resovist, NIR-IO, Resovist $+M F(p<0.001)$. ( $\downarrow$ ) Significant difference in livers between the group of NIR-IO+MF and Resovist +MF $(p<0.001)$. The biodistribution results was detected via ICP-OES after $24 \mathrm{~h}$ intravenously injection.

Other inorganic nanoparticles, including carbon nanostructures[91], quantum dots[92], and gold nanoparticles[33], can also be used for PTT. Our results provide evidence for an excellent magnetic targeting effect of the NIR-IO nanocrystals and diminished distribution of these nanoparticles in other reticuloendothelial system (RES) organs.
Additionally, the IO nanoparticles have Federal Drug Administration approval for clinical use.[21, 39, 93] Additionally, the clinical applications and studies of magnetic thermal therapy still foucus on hyperthermia model, which is a heat producing therapy via applying an external magnetic field acting on superparamagnetic iron oxide nanoparticles 
(SPIO) [94]. This model had entered clinical studies via MagForce (Berlin, Germany) in 2007, and recent clinical trials began to evaluate the hyperthmia therapy in patients with recurrent glioblastoma multiforme and metastatic bone tumors.[95] However, there were many cases or studies of clinical trails in the area of (SPIO) nanoparticles hyperthermia therapy, the limitations of this therapy still existed and must to be solved. The major clinical limitation of SPIO nanoparticles was too high treatment dosage $[96,97]$ ([Fe] are usually over $1 \mathrm{M}$ in the phase I study, which is almost or over ten folds than the dosage of this study used) due to SPIO nanoparticles had lower specific loss power (SLP, or heat dissipation per unit mass of magnetic material).[98] Although, SPIO nanoparticles with higher SLP value (near $1000 \mathrm{~W} / \mathrm{g}$ range) had been reported in the recent years, the heating performance of these SPIO nanoparticles had to reached its limit [85]. Therefore, to concern the clinical dosage and treatment efficacy, the photothermal therapy is might a potential treatment model in cancer therapy because its higher heating efficiency and lower treatment dosage. For biomedical applications, our in vivo results revealed the great potential of NIR-IO nanocrystals for use in clinical cancer theranostics due to the low treatment dosage and light doses required and their excellent PTT efficacy, MR contrast ability, high accumulation in the tumor area, and low cytotoxicity to other organs.

We also investigated the influence of the ligand used to synthesize the nanocrystals. The synthesis ligand citrate was replaced with a photosensitizer (dendrimer phthalocyanine, DPc). Figure S12 shows the TEM results obtained after using the photosensitizer to replace citrate. When larger amounts of the photosensitizer were added, variations similar to those observed for changes in the citrate concentration appeared. This result emphasizes the importance of the ligand-metal ion interactions, showing that compounds with groups that perform similar functions can provide the same function in our material synthesis, and it also shows that this technique can be used to prepare nanocrystals suitable for use in photodynamic or other types of therapy.

\section{Conclusion}

We used co-precipitation, partial oxidation approach to produce IO nanocrystals that display excellent NIR absorption and MR properties. Ligand effects on IO nanocrystals and crystalline of IO nanocrystals obviously influence the photothermal ability of NIR-IO. NIR-IO mediated PTT revealed efficient cancer cell membrane disruption and intracellular protein alterations for cell killing. With
MF targeting in tumor area, NIR-IO by intravenous injection resulted in excellent accumulation of nanocrystals in the tumor, lower RES distribution, obvious enhancement of MR $T_{2}$ contrast imaging, and great photothermal ablation ability. Most importantly, during the entire treatment, no noticeable toxicity was observed, indicating the good biocompatibility of prepared NIR-IO nanocrystals. Therefore, NIR-IO nanocrystals have a promising potential for clinical photothermal cancer treatment and MR imaging.

\section{Materials and Methods}

Materials: The reagents used and their sources were as follows: ferrous sulfate heptahydrate $\left(\mathrm{FeSO}_{4} \cdot 7 \mathrm{H}_{2} \mathrm{O}, \geq 99 \%\right)$ (Sigma-Aldrich); trisodium citrate $(99.5-100.5 \%$, J. T. Baker); benzene1,3,5-tri-carboxylic acid (trimesic acid (TMA), 98\%) (Alfa Aesar); sodium hydroxide $(\mathrm{NaOH}, 99.0 \%)$ (Riedel-de Haën); ethanol (EtOH, 99.9\%) (J. T. Baker); hydrazine monohydrate $\left(\mathrm{N}_{2} \mathrm{H}_{4} \cdot \mathrm{H}_{2} \mathrm{O}, \quad 98 \%\right)$ (Sigma-Aldrich); sodium nitrate $\left(\mathrm{NaNO}_{3}, \geq 99.5 \%\right)$ (Sigma-Aldrich); and dendrimer phthalocyanine (DPcZn, a $2^{\text {nd }}$ generation acrylic ether dendrimer with zinc(II) in the phthalocyanine center and 32 carboxylic groups on its periphery) (a generous gift from Professor Kazunori Kataoka, University of Tokyo, Japan).

Preparation of Citrate-Cojugated NIR-IO Nanocrystals: Eighty milligrams of $\mathrm{FeSO}_{4} \cdot 7 \mathrm{H}_{2} \mathrm{O}$ and trisodium citrate $(110,22,2.2 \mathrm{mg}$ ) were dissolved in 15 $\mathrm{mL}$ of deionized water with stirring, immediately transferred to $\mathrm{N}_{2}$ flask and purged with nitrogen for $10 \mathrm{~min}$. The solution was then heated to $85^{\circ} \mathrm{C}$, and $0.377 \mathrm{M} \mathrm{NaOH}$ solution containing $0.0185 \mathrm{mM}$ TMA and $1.2 \mathrm{M} \mathrm{N}_{2} \mathrm{H}_{4}$ was added dropwise. The rate of addition of $\mathrm{NaOH}$ was $2 \mathrm{~mL} \mathrm{~min}^{-1}$. After the $\mathrm{NaOH}$ addition, the solution was allowed to react for 1 hour, during which time the color changed from brown to black. The solution was then cooled to room temperature, and the as-synthesized IO products were removed by dialysis for 4 days against deionized water and separation via magnetic attraction. The IO products were then dispersed in $5 \mathrm{~mL}$ of deionized water for future use.

Preparation of DPcZn-Conjugated IO Nanocrystals: This preparation process used DPcZn to replace citrate: $8 \mathrm{mg}$ of $\mathrm{FeSO}_{4} 7 \mathrm{H}_{2} \mathrm{O}$ and various amounts of DPcZn (9.9 or $66 \mathrm{mg}$ ) were dissolved in 15 $\mathrm{mL}$ of deionized water with stirring and protection from light, then immediately transferred to $\mathrm{N}_{2}$ flask and purged with nitrogen for $10 \mathrm{~min}$. The solution was then heated to $85^{\circ} \mathrm{C}$, and $0.377 \mathrm{M} \mathrm{NaOH}$ solution containing $0.00185 \mathrm{mM}$ TMA and $0.12 \mathrm{M} \mathrm{N}_{2} \mathrm{H}_{4}$ was added dropwise. The nanocrystals formed during this process were purified as described above. 
Photothermal Effect Evaluation for 808-nm and 660-nm Laser Irradiation: The concentrations of $\mathrm{Fe}$ in the $\mathrm{Fe}_{3} \mathrm{O}_{4}$ nanoparticle solutions were determined quantitatively by absorbance spectrophotometry. After the concentrations of the solutions were determined, $100 \mu \mathrm{L}$ of solutions containing various concentrations of $\mathrm{Fe}_{3} \mathrm{O}_{4}$ nanocrystals were placed in Eppendorf tubes. Then, 808- and $660 \mathrm{~nm}$ continuous-wave $(\mathrm{CW})$ diode lasers (the power density of the 808-nm laser was $1.5 \mathrm{~W} \mathrm{~cm}^{-2}$, and that of the $660-\mathrm{nm}$ laser was $0.2 \mathrm{~W} \mathrm{~cm}^{-2}$ ) were used to irradiate the solutions. The temperature was measured using a thermographic camera (TVS-500 EX, NEX Avio Infrared Technologies Co., Ltd.).

Cell Line and Cell Culture Conditions: In the in vitro studies, HT-29 human colorectal adenocarcinoma cells (ATCC No: HTB-38 ${ }^{\mathrm{TM}}$ ) were used. HT-29 cells were grown in T-75 flasks (BD Falcon) in Dulbecco's modified Eagle's medium (DMEM; Gibco BRL, Gaithersburg, MD, USA) containing $1 \mathrm{mM}$ sodium pyruvate (Gibco BRL) and supplemented with $10 \%$ fetal bovine serum (FBS; Gibco BRL) and 1\% penicillin-streptomycin-neomycin solution (PSN; Gibco BRL) at $37{ }^{\circ} \mathrm{C}$ in a $5 \% \mathrm{CO}_{2}$ atmosphere.

Photothermal Effect, Cytotoxicity and Biochemical Molecular Studies In vitro: To evaluate photothermal efficacy of NIR-activated iron oxide nanoparticle in vitro. HT-29 cells were seed in $6 \mathrm{~cm}$ diameter culture dish with culture medium. Each dish contained $10^{5}$ cells then put these culture dishes into incubator and waited $24 \mathrm{~h}$ to let cells adhesion. The cells were then treated with NIR-activated IO nanocrystals with various concentrations $(140,70,35$, $17.5 \mu \mathrm{g} \mathrm{mL}^{-1}$ ) and incubated for an additional $24 \mathrm{~h}$ at $3{ }^{\circ} \mathrm{C}$. At the specified time point, the treatment medium was removed, the cells were rinsed three times with PBS. After step of washing cells with PBS, cells were collected into an eppendorf by using $0.25 \%$ trypsin-EDTA and then replaced trypsin-EDTA to fresh culture medium. The collected cells were exposed to $808 \mathrm{~nm}$ continuous wave diode laser (the power density of $808 \mathrm{~nm}$ laser is $1.5 \mathrm{~W} \mathrm{~cm}^{-2}$ ) for 5 minutes. The temperature alteration was recorded by thermographic camera. The exposed cells were planted into 96-well plates at the density of 8000 cells per well and then incubated for $24 \mathrm{~h}$. To investigate the cell viability, alamar blue assay was performed. The original culture medium in each well was removed and replaced with $100 \mu \mathrm{L}$ of culture medium containing $10 \mu \mathrm{L}$ of alamarBlue ${ }^{\circledR}$ reagent (Molecular Probes, Invitrogen). The 96-well plate was then incubated for $3 \mathrm{~h}$ at $37^{\circ} \mathrm{C}$, during which time the resazurin (non-fluorescent) was reduced to resorufin (fluorescent). The cell viability was quantified using a scanning multiwell ELISA reader (SpectraMax ${ }^{\circledR}$ M2e, Molecular Devices, USA) at an excitation wavelength of $570 \mathrm{~nm}$ and a fluorescence emission wavelength of $590 \mathrm{~nm}$. We also used propidium iodine (PI; Molecular Probes, Invitrogen) to verify the photothermal effect of NIR-activated IO nanocrystals on cancer cells. For this measurement, HT-29 cells were treated with $140 \mu \mathrm{g} \mathrm{mL}^{-1}$ nanocrystals and then irradiated (or not) for $5 \mathrm{~min}$ with a $\mathrm{CW}$ diode laser $(808 \mathrm{~nm})$ and incubated for an additional $24 \mathrm{~h}$ at $37^{\circ} \mathrm{C}$. The cells were then stained with PI and imaged by confocal laser scanning microscopy (CLSM; Leica-SP5, Leica Microsystems Heidelberg GmbH, Germany). For biochemical molecular investigation, HT-29 cells with or without NIR-IO-mediated PTT were seeded $5 \times 10^{4}$ cells on low-e slides and incubated for $24 \mathrm{~h}$, respectively. These adhered cell samples were washed using PBS, fixed using $4 / \%$ paraformaldehyde and then dried overnight for futher investigation. The Fourier transform infrared (FTIR) imaging of as-prepared cell samples were measured by synchrotron-based infrared microspectroscopy (SR-IMS; beamline 14A1, National Synchrotron Radiation Research Center, Taiwan). The spectra were recorded in reflectance mode from each sample section using a Thermo Nicolet 6700 spectrometer and a continuum infrared microscope with the following settings: mid-infrared range $3600-650 \mathrm{~cm}^{-1}$, resolution $4 \mathrm{~cm}^{-1}$, step size $10 \mu \mathrm{m}$, aperture $15^{*} 15 \mu \mathrm{m}^{2}$ and 128 scans. Peak positioning, deconvolution, and baseline corrections were performed using OMNIC peak-resolving software.

Animal and In vivo Examinations: The in vivo experimental protocols were approved by the Institutional Animal Care and Use Committee of National Chung Hsing University (IACUC of NCHU). Female BALB/cAnN.Cg-Foxn1 1 $/$ CrlNarl nude mice (4-5 weeks old, $20 \pm 2 \mathrm{~g}$ ) were obtained from the National Laboratory Animal Center (Taiwan). The mice were kept in an air-conditioned facility under an artificial light-dark cycle and provided with standard food and filtered water. The mice were acclimated to this environment for at least three days prior to subcutaneous injection in the right hindquarter with 2 $\times 10^{6}$ HT-29 cells suspended in serum-free DMEM. The tumor size was calculated as $1 / 2(4 \Pi / 3)(\mathrm{L} / 2)$ $(\mathrm{W} / 2) \mathrm{H}$, where $\mathrm{L}$ is the length, $\mathrm{W}$ is the width, and $\mathrm{H}$ is the height of the tumor. Treatment was initiated when the tumor reached a volume of $150-200 \mathrm{~mm}^{3}$.

Photothermal Effect and MRI Studied In vivo: To study the photothermal effect and MRI in vivo, we used two different methods. Mice bearing HT-29 tumors approximately $200 \mathrm{~mm}^{3}$ in size were treated with $100 \mu \mathrm{L}$ of PBS (Control) or NIR-IO (9.5 mg mL-1) via intravenous injection or with $100 \mu \mathrm{L}$ of Resovist ${ }^{\circledR}$ 
(3.5 mg mL-1) or NIR-IO (3.5 $\left.\mathrm{mg} \mathrm{mL}^{-1}\right)$ via intratumoral injection for photothermal effect investigation. In the experimental group that received intravenous injection, we attached a small magnet to the tumor $24 \mathrm{~h}$ after the intravenous injection. At specific times thereafter, the tumors were exposed to an 808-nm NIR laser. In the intratumoral injection group, the tumors were exposed to the $808-\mathrm{nm}$ NIR laser immediately after intratumoral injection. The power density of the $808-\mathrm{nm}$ NIR laser $\left(1.5 \mathrm{~W} \mathrm{~cm}^{-2}\right.$ for $10 \mathrm{~min}$ ) was the same for the intravenous and intratumoral injection groups. During irradiation, the temperature of the tissue was recorded by a thermographic camera. To evaluate the quality of magnetic resonance imaging (MRI), PBS (control; 100 $\mu \mathrm{L})$, Resovist ${ }^{\circledR}\left(100 \mu \mathrm{L} ; 9.5 \mathrm{mg} \mathrm{mL}^{-1}\right)$, and NIR-IO (100 $\left.\mu \mathrm{L} ; 9.5 \mathrm{mg} \mathrm{mL}^{-1}\right)$ were intravenously injected into HT-29 tumor-bearing mice. After intravenous injection and exposure to the magnetic targeting field for $24 \mathrm{~h}$, the tumor-bearing mice were subjected to MR imaging using a $7 \mathrm{~T}$ MRI (Bruker, USA) under halothane gas anesthesia before and after injection. TurboRARE-T2 pulse sequences $(\mathrm{TR} / \mathrm{TE}=5000 \mathrm{~ms} / 56$ ms, flip angle $=180^{\circ}$, matrix size $=256 \times 128$ ) were used for $T_{2}$-weighted imaging. The slice thickness was 1 $\mathrm{mm}$ with a $1 \mathrm{~mm}$ gap, and the field of view (FOV) was $9 \times 3.5 \mathrm{~cm}^{2}$ for coronal scanning.

Antitumor Efficacy of NIR-IO Nanocrystals and NIR-IO Nanocrystals with MF TargetingMediated PTT: To investigate the antitumor efficacy of our treatments, mice bearing HT-29 tumors approximately $150 \mathrm{~mm}^{3}$ in size were randomized into five treatment groups ( $\mathrm{n}=3$ per group): $\mathrm{PBS}, \mathrm{PBS}$ with laser irradiation, NIR-IO + MF targeting, NIR-IO with laser irradiation, and NIR-IO + MF targeting with laser irradiation. The animals were treated with 0.1 $\mathrm{mL}$ of PBS and $0.1 \mathrm{~mL}$ of NIR-IO $\left(\mathrm{Fe}_{3} \mathrm{O}_{4}, 9.5 \mathrm{mg} \mathrm{mL}^{-1}\right)$ via intravenous injection (day 0 ). At the end of the treatment, a small magnet was attached to the tumor of the MF targeting groups. Twenty-four hours after intravenous injection, the magnet was removed and the tumor was irradiated with an 808-nm NIR laser $\left(1.5 \mathrm{~W} \mathrm{~cm}^{-2}\right)$ for $10 \mathrm{~min}$. The percentage of tumor growth inhibition (TGI\%) was calculated from the relative tumor volume on day 15 . The tumor size and body weight were measured every 2 or 3 days for the duration of the experiment.

Histological Analysis of Tumor Tissue: Tumors were excised and weighed after the mice were euthanized. For hematoxylin and eosin (H\&E), the tumor tissue was fixed in formalin and embedded in paraffin. Then, paraffin-embedded $3-\mu \mathrm{m}$ tumor sections were deparaffinized, rehydrated, and incubated in $3 \% \mathrm{H}_{2} \mathrm{O}_{2}$ to inhibit endogenous peroxidase activity. The sections were also counterstained with hematoxylin and eosin (H\&E) or hydrochloric acid $(20 \%)$. The stained sections were monitored at low power (40X) and counted at high magnification (400X). Images of the stained sections were acquired using a light microscope (BX 50, Olympus) equipped with a digital camera (DP 20, Olympus) and used to analyze the damage to the tissue structure and the NIR-IO nanocrystal accumulation in the tissue.

Biodistribution of NIR-IO nanocrystals: The quantitative analysis of NIR-IO, Resovist, NIR-IO+MF, Resovist+MF ( $\mathrm{n}=4$ per group) was analyzed in female BALB/c nude mice bearing HT-29 tumors. The agent was administered intravenously as a single dose ([Fe]: $18 \mathrm{mg} \mathrm{kg}^{-1}$ ). Mice were sacrificed by cervical dislocation $24 \mathrm{~h}$ after drug administration. Tumor, heart, liver, spleen, lung and kidney collected from each mouse and snap frozen in liquid nitrogen. These organs were lyophilized for $24 \mathrm{~h}$ in a freeze dryer and then weighted. The samples were then dissolved in the $20 \%$ nitric acid for $48 \mathrm{~h}$. All samples were spun at $16000 \mathrm{~g}$ in a centrifuge for $30 \mathrm{~min}$ and the supernatants were analyzed for iron content by ICP-OES (Thermal Fisher Scientific, iCAPTM 7400). All results were normalized in the units of percentage of injected dose per gram (\% ID per g) of tissue.

Characterization of NIR-IO: Electron micrographs were obtained using transmission electron microscopes (TEM, JEM 1400 and JEM 2010, JEOL Ltd., Japan). A UV-Vis spectrophotometer (HITACHI U-300, Tokyo, Japan) was used to determine the absorption characteristics of the samples. Fe ions were quantified using an atomic absorption spectrophotometer (GBC Scientific 932 AA, Melbourne, Australia). IR spectra were measured using a $\mathrm{KBr}$ plate in a FTIR spectrometer (Thermo Nicolet 6700, Madison, WI, USA). The magnetic properties of the NIR-IO nanocrystals were examined with a vibration sample magnetometer (VSM, LakeShore). The size of NIR-IO nanocrystals was measured using a Zetasizer Nano ZS apparatus (Malvern Instruments, Worcestershire, UK).

Statistical Analysis: The data are expressed as the mean $\pm \mathrm{SD}$. The tumor volumes for each group measured at different time points are summarized as the mean values and SDs. Group effects on tumor volume were tested using a linear mixed model with Bonferroni correction and are presented as the estimated marginal means (EM mean values) and the corresponding 95\% confidence interval (CI) for tumor volume, with adjustment for time effects. Statistical significance was set at 0.05 . Statistical analyses were performed using the SPSS 15.0 software package (SPSS Inc., Chicago, IL, USA). 


\section{Supplementary Material}

Supplementary figures and tables. http://www.ntno.org/v03p0236s1.pdf

\section{Acknowledgements}

This research was supported by grants from Ministry of Science and Technology of Republic of China (R.O.C) (MOST 103-2113-M-005-008-MY3). We also thank Prof. Kazunori Kataoka for help with DPc support at the University of Tokyo, Japan.

\section{Competing Interests}

The authors have declared that no competing interest exists.

\section{References}

1. Naumova AV, Modo M, Moore A, Murry CE, Frank JA. Clinical imaging in regenerative medicine. Nat Biotech. 2014; 32: 804-18.

2. Zou L, Wang H, He B, Zeng L, Tan T, Cao H, et al. Current approaches of photothermal therapy in treating cancer metastasis with nanotherapeutics. Theranostics. 2016; 6: 762-72.

3. Feng T, Ai X, An G, Yang P, Zhao Y. Charge-convertible carbon dots for imaging-guided drug delivery with enhanced in vivo cancer therapeutic efficiency. ACS Nano. 2016; 10: 4410-20.

4. Wang J, Liu J, Liu Y, Wang L, Cao M, Ji Y, et al. Gd-hybridized plasmonic au-nanocomposites enhanced tumor-interior drug permeability in multimodal imaging-guided therapy. Adv Mater. 2016; 28: 8950-8.

5. Liu T-M, Conde J, Lipinski T, Bednarkiewicz A, Huang C-C. Revisiting the classification of NIR-absorbing/emitting nanomaterials for in vivo bioapplications. NPG Asia Mater. 2016; 8: e295.

6. Weissleder R, Nahrendorf $M$, Pittet MJ. Imaging macrophages with nanoparticles. Nat Mater. 2014; 13: 125-38.

7. Li C. A targeted approach to cancer imaging and therapy. Nat Mater. 2014; 13: 110-5.

8. Liang S, Li C, Zhang C, Chen Y, Xu L, Bao C, et al. CD44v6 monoclonal antibody-conjugated gold nanostars for targeted photoacoustic imaging and plasmonic photothermal therapy of gastric cancer stem-like cells. Theranostics. 2015; 5: 970-84.

9. Liu X, Zhang X, Zhu M, Lin G, Liu J, Zhou Z et al. PEGylated Au@Pt nanodendrites as novel theranostic agents for computed tomography imaging and photothermal/radiation synergistic therapy. ACS Applied Materials \& Interfaces. 2017; 9: 279-85.

10. Cheng L, Yang K, Li Y, Chen J, Wang C, Shao M, et al. Facile preparation of multifunctional upconversion nanoprobes for multimodal imaging and dual-targeted photothermal therapy. Angew Chem. 2011; 123: 7523-8.

11. Lu W, Singh AK, Khan SA Senapati D, Yu H Ray PC Gold nano-popcorn-based targeted diagnosis, nanotherapy treatment, and in situ monitoring of photothermal therapy response of prostate cancer cells using surface-enhanced raman spectroscopy. J Am Chem Soc. 2010; 132: 18103-14.

12. Jang B, Park J-Y, Tung C-H, Kim I-H, Choi Y. Gold nanorod-photosensitizer complex for near-infrared fluorescence imaging and photodynamic/photothermal therapy in vivo. ACS Nano. 2011; 5: 1086-94.

13. Huang CC, Liu TM. Controlled Au-polymer nanostructures for multiphoton imaging, prodrug delivery, and chemo-photothermal therapy platforms. ACS Applied Materials \& Interfaces. 2015; 7: 25259-69.

14. Daniele MA, Shaughnessy ML, Roeder R, Childress A, Bandera YP, Foulger S. Magnetic nanoclusters exhibiting protein-activated near-infrared fluorescence. ACS Nano. 2012; 7: 203-13.

15. Xie J, Liu G, Eden HS, Ai H, Chen X. Surface-engineered magnetic nanoparticle platforms for cancer imaging and therapy. Acc Chem Res. 2011; 44: 883-92.

16. Reddy LH, Arias JL, Nicolas J, Couvreur P. Magnetic nanoparticles: design and characterization, toxicity and biocompatibility, pharmaceutical and biomedical applications. Chem Rev. 2012; 112: 5818-78.

17. Della Rocca J, Liu D, Lin W. Nanoscale metal-organic frameworks for biomedical imaging and drug delivery. Acc Chem Res. 2011; 44: 957-68.

18. Wilson MW, Robert K. Kerlan J, Fidelman NA, Venook AP, LaBerge JM, Koda J, et al. Hepatocellular carcinoma: regional therapy with a magnetic targeted carrier bound to doxorubicin in a dual $\mathrm{mr}$ imaging/ conventional angiography suite -initial experience with four patients. Radiology. 2004; 230: 287-93.

19. Fang J, Nakamura H, Maeda H. The EPR effect: Unique features of tumor blood vessels for drug delivery, factors involved, and limitations and augmentation of the effect. Adv Drug Deliv Rev. 2011; 63: 136-51.
20. Cheng L, Yang $\mathrm{K}$, Li $\mathrm{Y}$, Zeng $\mathrm{X}$, Shao $\mathrm{M}$, Lee ST, et al. Multifunctional nanoparticles for upconversion luminescence/MR multimodal imaging and magnetically targeted photothermal therapy. Biomaterials. 2012; 33: 2215-22.

21. Li Z, Wang C, Cheng L, Gong H, Yin S, Gong Q, et al. PEG-functionalized iron oxide nanoclusters loaded with chlorin e6 for targeted, NIR light induced, photodynamic therapy. Biomaterials. 2013; 34: 9160-70.

22. Zhang F, Braun GB, Pallaoro A, Zhang Y, Shi Y, Cui D, et al. Mesoporous multifunctional upconversion luminescent and magnetic "nanorattle" materials for targeted chemotherapy. Nano Lett. 2012; 12: 61-7.

23. Zhang F, Braun GB, Pallaoro A, Zhang Y, Shi Y, Cui D, et al. Mesoporous multifunctional upconversion luminescent and magnetic "nanorattle" materials for targeted chemotherapy. Nano Lett. 2011; 12: 61-7.

24. Gupta AK, Gupta M. Synthesis and surface engineering of iron oxide nanoparticles for biomedical applications. Biomaterials. 2005; 26: 3995-4021.

25. Laurent S, Forge D, Port M, Roch A, Robic C, Vander Elst L, et al. Magnetic iron oxide nanoparticles: synthesis, stabilization, vectorization, physicochemical characterizations, and biological applications. Chem Rev. 2008; 108: 2064-110.

26. Zhou Z, Sun Y, Shen J, Wei J, Yu C, Kong B, et al. Iron/iron oxide core/shell nanoparticles for magnetic targeting MRI and near-infrared photothermal therapy. Biomaterials. 2014; 35: 7470-8

27. Liao MY, Lai PS, Yu HP, Lin HP, Huang CC. Innovative ligand-assisted synthesis of NIR-activated iron oxide for cancer theranostics. Chem Commun. 2012; 48: 5319-21.

28. Liao MY, Wu CH, Lai PS, Yu J, Lin H-P, Liu TM, et al. Surface state mediated nir two-photon fluorescence of iron oxides for nonlinear optical microscopy. Adv Funct Mater. 2013; 23: 2044-51.

29. Vogel A, Venugopalan V. Mechanisms of pulsed laser ablation of biological tissues. Chem Rev. 2003; 103: 577-644.

30. Sotiriou GA, Starsich F, Dasargyri A, Wurnig MC, Krumeich F, Boss A, et al. Photothermal killing of cancer cells by the controlled plasmonic coupling of silica-coated au/fe2o3 nanoaggregates. Adv Funct Mater. 2014; 24: 2818-27.

31. O'Neal DP, Hirsch LR, Halas NJ, Payne JD, West JL. Photo-thermal tumor ablation in mice using near infrared-absorbing nanoparticles. Cancer Lett. 2004; 209: 171-6.

32. Tian B, Wang C, Zhang S, Feng L, Liu Z. Photothermally enhanced photodynamic therapy delivered by nano-graphene oxide. ACS Nano. 2011; 5: 7000-9.

33. Lin J, Wang S, Huang P, Wang Z, Chen S, Niu G, et al. Photosensitizer-loaded gold vesicles with strong plasmonic coupling effect for imaging-guided photothermal/photodynamic therapy. ACS Nano. 2013; 7: 5320-9.

34. Lambert TN, Andrews NL, Gerung H, Boyle TJ, Oliver JM, Wilson BS, et al. Water-soluble germanium $(0)$ nanocrystals: cell recognition and near-infrared photothermal conversion properties. Small. 2007; 3: 691-9.

35. Tian Q, Tang M, Sun Y, Zou R, Chen Z, Zhu M, et al. Hydrophilic flower-like $\mathrm{CuS}$ superstructures as an efficient $980 \mathrm{~nm}$ laser-driven photothermal agent for ablation of cancer cells. Adv Mater. 2011; 23: 3542-7.

36. Nikoobakht B, El-Sayed MA. Preparation and growth mechanism of gold nanorods (nrs) using seed-mediated growth method. Chem Mater. 2003; 15: 1957-62

37. Sepúlveda B, Angelomé PC, Lechuga LM, Liz-Marzán LM. LSPR-based nanobiosensors. Nano Today. 2009; 4: 244-51.

38. Shen S, Kong F, Guo X, Wu L, Shen H, Xie M, et al. CMCTS stabilized Fe3O4 particles with extremely low toxicity as highly efficient near-infrared photothermal agents for in vivo tumor ablation. Nanoscale. 2013; 5: 8056-66.

39. Chu M, Shao Y, Peng J, Dai X, Li H, Wu Q, et al. Near-infrared laser light mediated cancer therapy by photothermal effect of $\mathrm{Fe} 3 \mathrm{O} 4$ magnetic nanoparticles. Biomaterials. 2013; 34: 4078-88.

40. Lai S-M, Chiou Y-C, Chen G-F, Liao M-Y, Tzen JTC, Lai PS. Enhanced nuclear localization of photosensitizer using artificial oil bodies for photodynamic therapy. Smart Science. 2016; 4: 167-72.

41. Zhao B, Itkis ME, Niyogi $\mathrm{S}, \mathrm{Hu} \mathrm{H}$, Zhang J, Haddon RC. Study of the extinction coefficients of single-walled carbon nanotubes and related carbon materials. The Journal of Physical Chemistry B. 2004; 108: 8136-41.

42. Bee A, Massart R, Neveu S. Synthesis of very fine maghemite particles. J Magn Magn Mater. 1995; 149: 6-9.

43. Baumgartner J, Dey A, Bomans PHH, Le Coadou C, Fratzl P, Sommerdijk NAJM, et al. Nucleation and growth of magnetite from solution. Nat Mater. 2013; 12: 310-4.

44. Barnakov YA, Scott BL, Golub V, Kelly L, Reddy V, Stokes KL. Spectral dependence of Faraday rotation in magnetite-polymer nanocomposites. J Phys Chem Solids. 2004; 65: 1005-10.

45. He YP, Miao YM, Li CR, Wang SQ, Cao L, Xie SS, et al. Size and structure effect on optical transitions of iron oxide nanocrystals. Physical Review B. 2005; 71: 125411

46. Bronstein LM, Huang X, Retrum J, Schmucker A, Pink M, Stein BD, et al. Influence of iron oleate complex structure on iron oxide nanoparticle formation. Chem Mater. 2007; 19: 3624-32.

47. Sadat ME, Baghbador MK, Dunn AW, Wagner HP, Ewing RC, Zhang J, et al. Photoluminescence and photothermal effect of $\mathrm{Fe} 3 \mathrm{O} 4$ nanoparticles for medical imaging and therapy. Appl Phys Lett. 2014; 105: 091903.

48. Yamashita M, Akai T, Sawa R, Abe J, Matsumura M. Effect of preparation procedure on redox states of iron in soda-lime silicate glass. J Non-Cryst Solids. 2008; 354: 4534-8 
49. Chen H, Burnett J, Zhang F, Zhang J, Paholak H, Sun D. Highly crystallized iron oxide nanoparticles as effective and biodegradable mediators for photothermal cancer therapy. J Mater Chem B. 2014; 2: 757-65.

50. Dan M, F Scott D, A Hardy P, J Wydra R, Zach Hilt J, Yokel R, et al. Block copolymer cross-linked nanoassemblies improve particle stability and biocompatibility of superparamagnetic iron oxide nanoparticles. Pharm Res. 2013; 30: 552-61.

51. Vereda F, de Vicente J, Hidalgo-Alvarez R. Oxidation of ferrous hydroxides with nitrate: A versatile method for the preparation of magnetic colloidal particles. J Colloid Interface Sci. 2013; 392: 50-6.

52. Hui C, Shen $\mathrm{C}$, Yang T, Bao L, Tian J, Ding H, et al. Large-scale $\mathrm{Fe}_{3} \mathrm{O}_{4}$ nanoparticles soluble in water synthesized by a facile method. J Phys Chem C. 2008; 112: 11336-9.

53. Guo X, Wu Z, Li W, Wang Z, Li Q, Kong F, et al. Appropriate size of magnetic nanoparticles for various bioapplications in cancer diagnostics and therapy. ACS Applied Materials \& Interfaces. 2016; 8: 3092-106.

54. Liu Y, Ai K, Liu J, Deng M, He Y, Lu L. Dopamine-melanin colloidal nanospheres: an efficient near-infrared photothermal therapeutic agent for in vivo cancer therapy. Adv Mater. 2013; 25: 1353-9.

55. Roper DK, Ahn W, Hoepfner M. Microscale heat transfer transduced by surface plasmon resonant gold nanoparticles. J Phys Chem C. 2007; 111: 3636-41.

56. Zheng M, Zhao P, Luo Z, Gong P, Zheng C, Zhang P, et al. Robust ICG theranostic nanoparticles for folate targeted cancer imaging and highly effective photothermal therapy. ACS Applied Materials \& Interfaces. 2014; 6: 6709-16.

57. Hessel CM, Pattani PV, Rasch M, Panthani MG, Koo B, Tunnell JW, et al. Copper selenide nanocrystals for photothermal therapy. Nano Lett. 2011; 11: $2560-6$

58. Tian Q, Hu J, Zhu Y, Zou R, Chen Z, Yang S, et al. Sub-10 nm Fe3O4@Cu2-xS core-shell nanoparticles for dual-modal imaging and photothermal therapy. J Am Chem Soc. 2013; 135: 8571-7.

59. Huang CC, Chang PY, Liu CL, Xu JP, Wu SP, Kuo WC. New insight on optical and magnetic $\mathrm{Fe} 3 \mathrm{O} 4$ nanoclusters promising for near infrared theranostic applications. Nanoscale. 2015;7:12689-697.

60. Li J, Han J, Xu T, Guo C, Bu X, Zhang H, et al. Coating urchinlike gold nanoparticles with polypyrrole thin shells to produce photothermal agents with high stability and photothermal transduction efficiency. Langmuir. 2013; 29: 7102-10

61. Lai SM, Hsiao JK, Yu HP, Lu CW, Huang CC, Shieh MJ, et al. Polyethylene glycol-based biocompatible and highly stable superparamagnetic iron oxide nanoclusters for magnetic resonance imaging. J Mater Chem. 2012; 22: 15160-7.

62. Xuan S, Wang Y-XJ, Yu JC, Cham-Fai Leung K. Tuning the Grain Size and Particle Size of Superparamagnetic Fe3O4 Microparticles. Chem Mater. 2009; 21: 5079-87.

63. Arbab AS, Bashaw LA, Miller BR, Jordan EK, Lewis BK, Kalish H, et al. Characterization of biophysical and metabolic properties of cells labeled with superparamagnetic iron oxide nanoparticles and transfection agent for cellular MR imaging. Radiology. 2003; 229: 838-46.

64. Pelaz B, Grazu V, Ibarra A, Magen C, del Pino P, de la Fuente JM. Tailoring the Synthesis and heating ability of gold nanoprisms for bioapplications. Langmuir. 2012; 28: 8965-70.

65. Bellisola G, Sorio C. Infrared spectroscopy and microscopy in cancer research and diagnosis. Am J Cancer Res. 2012; 2: 1-21.

66. Pérez-Hernández M, del Pino P, Mitchell SG, Moros M, Stepien G, Pelaz B, et al. Dissecting the molecular mechanism of apoptosis during photothermal therapy using gold nanoprisms. ACS Nano. 2015; 9: 52-61.

67. Melamed JR, Edelstein RS, Day ES. Elucidating the fundamental mechanisms of cell death triggered by photothermal therapy. ACS Nano. 2015; 9: 6-11.

68. Kong J, Yu S. Fourier transform infrared spectroscopic analysis of protein secondary structures. Acta Biochimica et Biophysica Sinica. 2007; 39: 549-59.

69. Pijanka J, Sockalingum GD, Kohler A, Yang Y, Draux F, Parkes G, et al. Synchrotron-based FTIR spectra of stained single cells. Towards a clinical application in pathology. Lab Invest. 2010; 90: 797-807.

70. Ali K, Lu Y, Das U, Sharma RK, Wiebe S, Meguro K, et al. Biomolecular diagnosis of human glioblastoma multiforme using Synchrotron mid-infrared spectromicroscopy. Int J Mol Med. 2010; 26: 11-6.

71. Peng CL, Shih YH, Lee PC, Hsieh TMH, Luo TY, Shieh MJ. Multimodal image-guided photothermal therapy mediated by 188re-labeled micelles containing a cyanine-type photosensitizer. ACS Nano. 2011; 5: 5594-607.

72. Wang L, Lin X, Wang J, Hu Z, Ji Y, Hou S, et al. Novel insights into combating cancer chemotherapy resistance using a plasmonic nanocarrier: enhancing drug sensitiveness and accumulation simultaneously with localized mild photothermal stimulus of femtosecond pulsed laser. Adv Funct Mater. 2014; 24: 4229-39.

73. Grabinski $\mathrm{C}$, Schaeublin $\mathrm{N}$, Wijaya A, D'Couto $\mathrm{H}$, Baxamusa $\mathrm{SH}$, Hamad-Schifferli K, et al. Effect of gold nanorod surface chemistry on cellular response. ACS Nano. 2011; 5: 2870-9.

74. Calabrò, E, Magazù, S. Electromagnetic fields effects on the secondary structure of lysozyme and bioprotective effectiveness of trehalose. Advances in Physical Chemistry. 2012; 2012: 970369.

75. Calabrò, E, Magazù, S. Inspections of mobile phone microwaves effects on proteins secondary structure by means of fourier transform infrared spectroscopy. Journal of Electromagnetic Analysis and Applications. 2010; 2: $607-17$
76. Bauer R, Carrotta R, Rischel C, Øgendal L. Characterization and isolation of intermediates in $\beta$-lactoglobulin heat aggregation at high $\mathrm{pH}$. Biophys J. 2000; 79: 1030-8.

77. Feng Q, Zhang Y, Zhang W, Hao Y, Wang Y, Zhang H, et al. Programmed near-infrared light-responsive drug delivery system for combined magnetic tumor-targeting magnetic resonance imaging and chemo-phototherapy. Acta Biomater. 2017; 49: 402-13.

78. Liao J, Wei X, Ran B, Peng J, Qu Y, Qian Z. Polymer hybrid magnetic nanocapsules encapsulating IR820 and PTX for external magnetic field-guided tumor targeting and multifunctional theranostics. Nanoscale. 2017; 9: 2479-91.

79. Wang Z, Chang Z, Lu M, Shao D, Yue J, Yang D, et al. Shape-controlled magnetic mesoporous silica nanoparticles for magnetically-mediated suicide gene therapy of hepatocellular carcinoma. Biomaterials. 2018; 154: 147-57.

80. Guo X, Li W, Luo L, Wang Z, Li Q, Kong F, et al. External magnetic field-enhanced chemo-photothermal combination tumor therapy via iron oxide nanoparticles. ACS Applied Materials \& Interfaces. 2017; 9: 16581-93.

81. Arami $\mathrm{H}$, Khandhar A, Liggitt $\mathrm{D}$, Krishnan $\mathrm{KM}$. In vivo delivery, pharmacokinetics, biodistribution and toxicity of iron oxide nanoparticles. Chem Soc Rev. 2015; 44: 8576-607.

82. Cole AJ, David AE, Wang J, Galbán CJ, Hill HL, Yang VC. Polyethylene glycol modified, cross-linked starch-coated iron oxide nanoparticles for enhanced magnetic tumor targeting. Biomaterials. 2011; 32: 2183-93.

83. Hua MY, Liu HL, Yang HW, Chen PY, Tsai RY, Huang CY, et al. The effectiveness of a magnetic nanoparticle-based delivery system for $\mathrm{BCNU}$ in the treatment of gliomas. Biomaterials. 2011; 32: 516-27.

84. Park E-J, Kim H, Kim Y, Yi J, Choi K, Park K. Inflammatory responses may be induced by a single intratracheal instillation of iron nanoparticles in mice. Toxicology. 2010; 275: 65-71.

85. Espinosa A, Di Corato R, Kolosnjaj-Tabi J, Flaud P, Pellegrino T, Wilhelm C. Duality of iron oxide nanoparticles in cancer therapy: amplification of heating efficiency by magnetic hyperthermia and photothermal bimodal treatment. ACS Nano. 2016; 10: 2436-46.

86. Shen S, Wang S, Zheng R, Zhu X, Jiang X, Fu D, et al. Magnetic nanoparticle clusters for photothermal therapy with near-infrared irradiation. Biomaterials. 2015; 39: 67-74.

87. Ren X, Zheng R, Fang X, Wang X, Zhang X, Yang W, et al. Red blood cell membrane camouflaged magnetic nanoclusters for imaging-guided photothermal therapy. Biomaterials. 2016; 92: 13-24

88. Yang R-M, Fu C-P, Fang J-Z, Xu X-D, Wei X-H, Tang W-J, et al. Hyaluronan-modified superparamagnetic iron oxide nanoparticles for bimodal breast cancer imaging and photothermal therapy. International Journal of Nanomedicine. 2017; 12: 197-206.

89. Xie Y, Hou W, Song X, Yu Y, Huang J, Sun X, et al. Ferroptosis: process and function. Cell Death Differ. 2016; 23: 369.

90. Friedmann Angeli JP, Schneider M, Proneth B, Tyurina YY, Tyurin VA, Hammond VJ, et al. Inactivation of the ferroptosis regulator Gpx4 triggers acute renal failure in mice. Nat Cell Biol. 2014; 16: 1180.

91. Bhirde AA, Chikkaveeraiah BV, Srivatsan A, Niu G, Jin AJ, Kapoor A, et al. Targeted therapeutic nanotubes influence the viscoelasticity of cancer cells to overcome drug resistance. ACS Nano. 2014; 8: 4177-89.

92. Chu M, Pan X, Zhang D, Wu Q, Peng J, Hai W. The therapeutic efficacy of $\mathrm{CdTe}$ and CdSe quantum dots for photothermal cancer therapy. Biomaterials. 2012; 33: 7071-83.

93. Tian Q, Wang Q, Yao KX, Teng B, Zhang J, Yang S, et al. Multifunctional Polypyrrole@Fe3O4 nanoparticles for dual-modal imaging and in vivo photothermal cancer therapy. Small. 2014; 10: 1063-8.

94. Ivkov R. Magnetic nanoparticle hyperthermia: A new frontier in biology and medicine? Int J Hyperthermia. 2013; 29: 703-5.

95. Revia RA, Zhang M. Magnetite nanoparticles for cancer diagnosis, treatment, and treatment monitoring: recent advances. Mater Today. 2016; 19: 157-68.

96. Dutz S, Hergt R. Magnetic nanoparticle heating and heat transfer on a microscale: Basic principles, realities and physical limitations of hyperthermia for tumour therapy. Int J Hyperthermia. 2013; 29: 790-800.

97. Johannsen M, Gneveckow U, Thiesen B, Taymoorian $\mathrm{K}$, Cho $\mathrm{CH}$, Waldöfner $\mathrm{N}$, et al. Thermotherapy of prostate cancer using magnetic nanoparticles: feasibility, imaging, and three-dimensional temperature distribution. Eur Urol. 2007; 52: 1653-62.

98. Kozissnik B, Bohorquez AC, Dobson J, Rinaldi C. Magnetic fluid hyperthermia: Advances, challenges, and opportunity. Int J Hyperthermia. 2013; 29: 706-14. 